\title{
Sustainable Agriculture through Multidisciplinary Seed Nanopriming: Prospects of Opportunities and Challenges
}

\author{
Amruta Shelar ${ }^{1}$, Ajay Vikram Singh ${ }^{2, *}+\mathbb{D}$, Romi Singh Maharjan ${ }^{2}$, Peter Laux ${ }^{2}$, Andreas Luch ${ }^{2}$, \\ Donato Gemmati $^{3 \oplus}$, Veronica Tisato ${ }^{3}{ }^{\circledR}$, Shubham Pratap Singh ${ }^{4}$, Maria Fernanda Santilli ${ }^{5}$, Akanksha Shelar ${ }^{6}$, \\ Manohar Chaskar ${ }^{7}$ and Rajendra Patil ${ }^{8, *(1)}$
}

1 Department of Technology, Savitribai Phule Pune University, Pune 411007, India; amrutavijaykumarshelar@gmail.com

2 Department of Chemical and Product Safety, German Federal Institute for Risk Assessment (BfR), Max-Dohrn-Strasse 8-10, 10589 Berlin, Germany; Romi-Singh.Maharjan@bfr.bund.de (R.S.M.); Peter.Laux@bfr.bund.de (P.L.); Andreas.Luch@bfr.bund.de (A.L.)

3 Department of Translational Medicine, University of Ferrara, 44121 Ferrara, Italy; cet@unife.it (D.G.); veronica.tisato@unife.it (V.T.)

4 Faculty of Informatics, Otto von Guericke University, 39106 Magdeburg, Germany; shubhamp.singh@yahoo.com

5 The Nanoinformatics Innovation Centre, La Plata, Buenos Aires C1062, Argentina; mfsantilli@gmail.com

6 Department of Microbiology, Savitribai Phule Pune University, Pune 411007, India; akankshavijaykumar2@gmail.com

Citation: Shelar, A.; Singh, A.V.; Maharjan, R.S.; Laux, P.; Luch, A.; Gemmati, D.; Tisato, V.; Singh, S.P.; Santilli, M.F.; Shelar, A.; et al. Sustainable Agriculture through Multidisciplinary Seed Nanopriming: Prospects of Opportunities and Challenges. Cells 2021, 10, 2428. https://doi.org/10.3390/cells10092428

\section{Academic Editors:}

Suleyman Allakhverdiev, Alexander G. Ivanov and Marian Brestic

Received: 1 August 2021

Accepted: 12 September 2021

Published: 15 September 2021

Publisher's Note: MDPI stays neutral with regard to jurisdictional claims in published maps and institutional affiliations.

Copyright: (C) 2021 by the authors Licensee MDPI, Basel, Switzerland. This article is an open access article distributed under the terms and conditions of the Creative Commons Attribution (CC BY) license (https:// creativecommons.org/licenses/by/ $4.0 /)$.
7 Ramkrishna More Arts, Commerce and Science College, Pune 411044, India; dean.st@unipune.ac.in

8 Department of Biotechnology, Savitribai Phule Pune University, Pune 411007, India

* Correspondence: Ajay-Vikram.Singh@bfr.bund.de (A.V.S.); rpatil@unipune.ac.in (R.P.)

Abstract: The global community decided in 2015 to improve people's lives by 2030 by setting 17 global goals for sustainable development. The second goal of this community was to end hunger. Plant seeds are an essential input in agriculture; however, during their developmental stages, seeds can be negatively affected by environmental stresses, which can adversely affect seed vigor, seedling establishment, and crop production. Seeds resistant to high salinity, droughts and climate change can result in higher crop yield. The major findings suggested in this review refer nanopriming as an emerging seed technology towards sustainable food amid growing demand with the increasing world population. This novel growing technology could influence the crop yield and ensure the quality and safety of seeds, in a sustainable way. When nanoprimed seeds are germinated, they undergo a series of synergistic events as a result of enhanced metabolism: modulating biochemical signaling pathways, trigger hormone secretion, reduce reactive oxygen species leading to improved disease resistance. In addition to providing an overview of the challenges and limitations of seed nanopriming technology, this review also describes some of the emerging nano-seed priming methods for sustainable agriculture, and other technological developments using cold plasma technology and machine learning.

Keywords: seed priming; nanotechnology; germination; seed resistance; sustainability; cold plasma technology; machine learning

\section{Introduction}

World food production must increase $50 \%$ by 2050 to meet the needs of 9 billion people [1]. The growing food demand and rapidly changing climatic conditions across the world motivates us to look for technological solutions that can provide food security for the future generations. Seed is a primary requirement for crop production, which carries the genetic potential of the variations and determines the ultimate productivity. Therefore, seed production is always the basic pre-requisite of any food security undertaking. A resilient and climate hardened seed can give the maximum output to the farmers. To increase the 
seed vigor and crop production, different chemical-based fertilizers and pesticides are used extensively in agriculture. In light of leaching, degradation, hydrolysis, and pollution associated with conventional chemical-based practices, they are being discouraged [2].There is an urgent need to develop a sustainable technology that can contribute to the green revolution to address these growing concerns and to restore the damage caused to the ecosystem [3]. Seed priming is an innovative sustainable seed technology to increase the seed vigor and crop production without harming the ecosystem [4-7]. As mentioned in Figure 1, priming of seeds dates back to Theophrastus, (371-287 B.C.) who, observed during an investigation that soaking cucumber seeds in water causes their germination to be faster and more uniform than unprimed seeds (enquiry into plants, book VII, I.6). A similar preparation of cucumber seeds in honey and water for seed germination was reported by the Roman naturalist Gaius Plinius Secundus (23-79 A.D.) in Gaius' Encyclopedia (Gaius 1949-1954). The French botanist Oliver de Serres, in 1539-1619, found that soaking seeds in manure water for 2 days and drying them prior to sowing was an effective cure for poor crop growth. The osmo-priming process was tested on lettuce and cress seeds in seawater by Charles Darwin, who observed that the primed seeds germination was higher than that of non-primed seeds. By identifying the critical parameters of seed treatment, Ells (1963) presented the modern concept of seed priming. His experiments with nutrient solutions showed a high germination rate. Khodakovskaya et al. published one of the first studies to demonstrate the potential for nanomaterials to affect seed germination [8]. The latest innovative technique with potential application in seed priming is seed nanopriming, an important emerging seed technology that blends seed priming science with updated nanotechnology $[9,10]$. A lot of attention has recently been brought to the development and optimization of nanomaterials for application in agriculture, including improved growth, plant protection, and overall performance. Agricultural nanomaterials are still in a juvenile state in terms of their application to sustainable agriculture [11]. Nanomaterials will be applied to multiple functions in agriculture as the understanding of nanotechnology increases. It has been noticed that most agricultural lands are affected by abiotic stress factors such as salinity and drought, which is limiting plant distribution in the habitat [12]. In order to combat abiotic stress factors, engineered nanoparticles have been found to be a promising alternative [13]. Recent studies have shown that nanomaterials can significantly impact plant metabolism, genes expression, and antioxidant enzyme activity [14]. Abiotic stress can be improved by nanoparticles such as halloysite, cerium oxide, chitosan-selenium and titanium dioxide by enabling their antioxidant system to perform better [15-18]. The use of nanoparticles as seed priming agents has demonstrated encouraging results in the field of crop productivity and seed germination [19]. By using nanotechnology, it is possible to release priming agents at specific sites and in controlled ways, which is revolutionary for ecosystems, crop improvement, animal health, and pesticide use. Nanopriming is an ongoing effort to create nano-agrochemicals for releasing specific nutrients in a controlled manner, which maintains soil fertility. Using high quality seed detection technologies makes it more likely to identify a variety of better crops since seed quality is an important factor in crop production. An increasing number of effective methods are needed that can detect nanoprimed seed quality in a non-destructive, objective manner as quickly as possible. The presented review describes the potential application of engineered nanomaterials in seed nanopriming for sustainable agriculture and machine learning technology for detection and classification of nanoprimed seeds to improve crop production. 


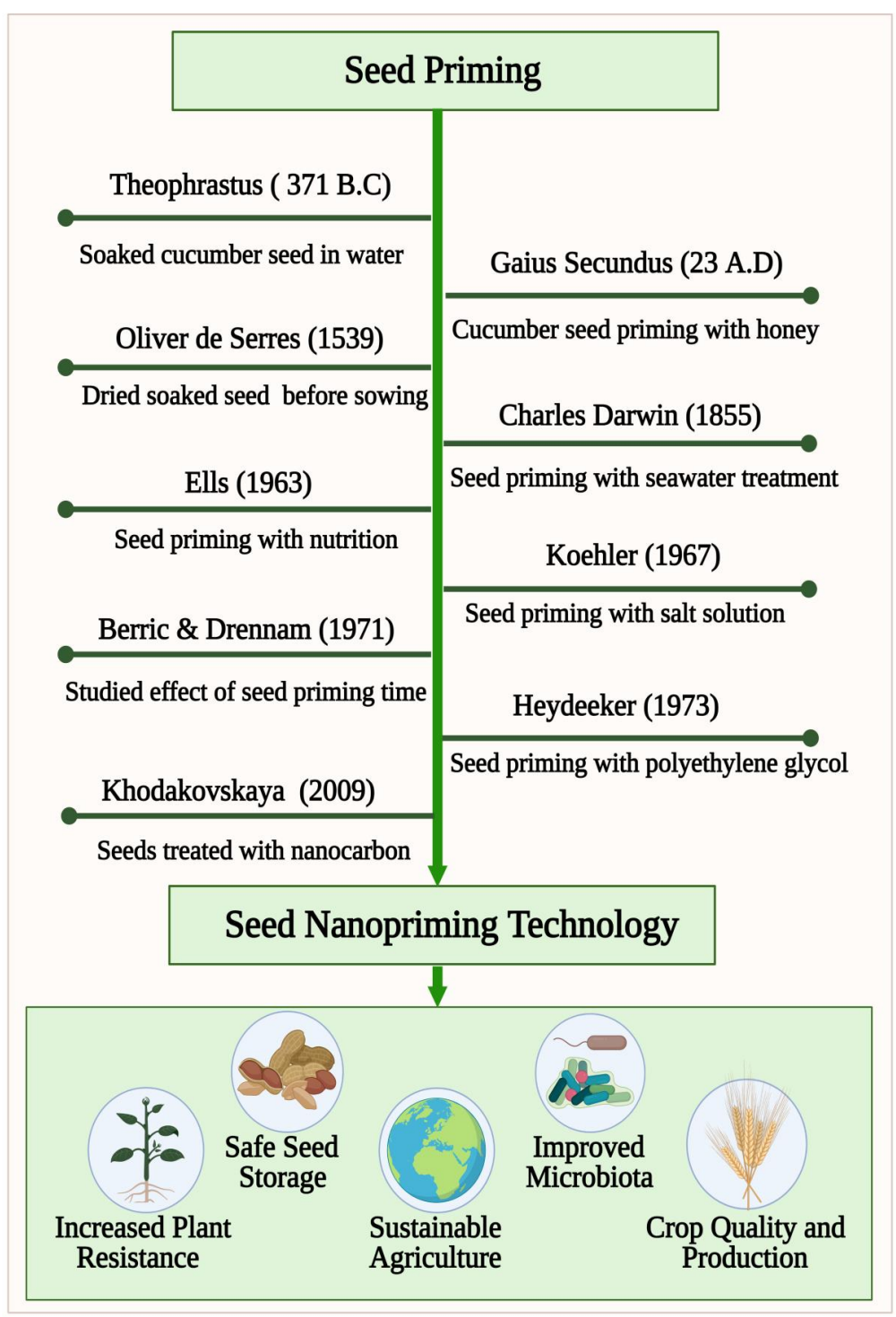

Figure 1. A timeline of seed priming development towards nanopriming technology to improve seed germination. For sustainable food production, nanopriming improves the ability to withstand environmental stressors, improves seed storage, and boosts microbiota.

\section{Seed Nanopriming Technology}

Seeds are miniature plants which, when fertilized, hatch into ovules containing both a germinating embryo and enough food to grow. A variety of treatments can be applied to a seed before planting in order to enhance its quality and potential yield. The process of priming seeds, in its broadest sense, involves soaking them in a solution where enough water is absorbed so that germination of the seed becomes possible, but not enough to allow the radicle to protrude through the seed coat [20]. Using this technique, seeds are advanced to an equal stage of germination to facilitate emergence from seed quickly and uniformly [21]. Thus, priming of seeds is a very important practice in order to ensure seed productivity [22]. Seed priming methods include hydro-priming, halo-priming, osmopriming, hormonal priming, solid matrix priming, and bio-priming to stimulate seeds, encourage germination, and reduce environmental stress. Among the most well-known and cost-effective pre-sowing seed priming methods, hydro-priming involves treating seeds with water before sowing. The seeds are soaked in water, then re-dried to their original moisture content [23]. The process of halo priming involves treating seeds with inorganic solutions such as sodium chloride, potassium nitrate, calcium chloride, and calcium 
sulphate to improve germination. A known application of halopriming during the germination, seedling emergence, emergence of plants, and growth of plants is well known [24]. In osmo-priming, seeds are soaked in different concentrations of osmotic solutions. Different osmotic solutions are used depending on the species, including sugar, polyethylene glycol, glycerol, sorbitol, and mannitol and then air drying is followed by sowing. Solutions containing low water potential facilitate seed imbibitions and, therefore, early stages of germination occur [25]. Hormonal-priming involves the use of hormone solutions to prime seeds. During hormonal priming, plant growth regulators are used to imbibe seeds that have direct effects on seed metabolism. Hormo-priming uses various regulators such as abscisic acid, salicylic acid, ascorbic acid, cytokinins, auxins, gibberellins, kinetin, ethylene, and polyamines [26]. In solid matrix priming (SMP or Matri-conditioning), seeds are mixed in known proportions with a solid material and water. Water-absorbing seeds will reach a point of equilibrium, precisely at which priming will take place. A thorough washing and drying follow the separated seeds from the matrix. A hydrated, metabolically active seed can then be achieved, which is an important germination step [27]. As an ecological approach, bio-priming involves seed inoculation with beneficial organisms to protect seed from disease. Seed treatment with this new trend involves hydrating seeds with beneficial microorganisms and improving germination procedures. In terms of disease management, biopriming provides better results than pelleting or coating [28]. Nanopriming, a technique that involves seeds soaking in nanomaterials, has been shown to facilitate germination and growth by allowing nanoparticles to penetrate the seed coat and increase water uptake. When compared with unprimed seeds or seeds treated with other priming agents, nanopriming improves storage, quality, seedling emergence, yields, and tolerance to environmental stress [7]. In addition, nanopriming of seeds can help prevent diseases caused by pathogens present in seeds. A high percentage of nanomaterials are retained on the seed surface as coatings when nanoparticles are absorbed, and a tortuous pathway prevents uncontrolled water uptake while reducing gas permeability, which leads to more stable seed storage. A nanopriming process can alter the metabolism of seeds and signalling pathways, thereby influencing their germination and growth. In addition to affecting almost every existing scientific field, nanoparticles can gain significant impact on agricultural sustainability by being introduced to the agricultural domain [7]. Studies have demonstrated that nanoparticle application can stimulate germination and growth of plants in numerous ways. Nanoparticles are effective because of their small size and unique physio-chemical properties, which make them an ideal seed priming agent [21]. Nanoparticles are molecular or atomic aggregates that have a measured dimension between $1 \mathrm{~nm}$ and $100 \mathrm{~nm}$ and which may produce significantly higher chemical and physical properties than typical bulk materials [29]. It is important to note that nanomaterials have a wide range of physio-chemical properties depending on the shape, size, surface area, surface/volume ratio, chemical behavior, particle charge, production method, coating, and so forth (as shown in Figure 2A). The unique features of nanomaterials, such as their high surface to mass ratio, enables them to enhance catalysis and deliver materials of interest, as well as adsorb substances of interest. The nanopriming process triggers a special metabolic reaction that is naturally triggered during the early stages of germination, as shown in Figure 2B. It increases seed germination, by modulating the metabolism of seed, which leads to enhanced water uptake, starch hydrolysis rate, cell wall loosening, endosperm weakening, rapid embryo growth, and rapid root-shoot development. The nanopriming method improves the emergence of seedlings, their growth, production, and quality [30]. The cellular and molecular mechanisms of plant interaction with the environment are also modulated by seed nanopriming. The goal of using nanoparticles in agriculture and natural ecosystems is to increase the performance and sustainability of plants and soil by using less of the input parameters defined above [31,32]. It is important to include different factors that affect priming success, such as the amount of water in the soil, the kind of priming treatment, the amount of time the seeds are exposed to the treatment, and the conditions in which the seeds are stored. Numerous studies have demonstrated 
the ability of nanoparticles to penetrate seed coats and enhance water uptake over time, which facilitates germination and flowering [33,34]. As seed pretreatment agents, several metal-metal oxide nanoparticles and carbon-based nanoparticles have been applied to enhance germination and seedling growth of some crops and to strengthen their stress tolerance [35-37]. Seed priming, in which seeds are re-dried to their original moisture content before planting, has been used in only a few studies, but it is not widely used. In this case, seed nanopriming would provide a different mechanism to that of pre-sowing seed treatment without drying. Additionally, comprehensive studies have not been conducted on the physiological and molecular mechanisms of nanopriming on seed germination, thus there are many unanswered questions, particularly concerning the mechanism behind nanoparticles-induced seed germination. A summary of the types of nanoparticles that are used for seed priming is shown in Table 1, with their potential effects as stimulants or protective against biotic and abiotic stress.

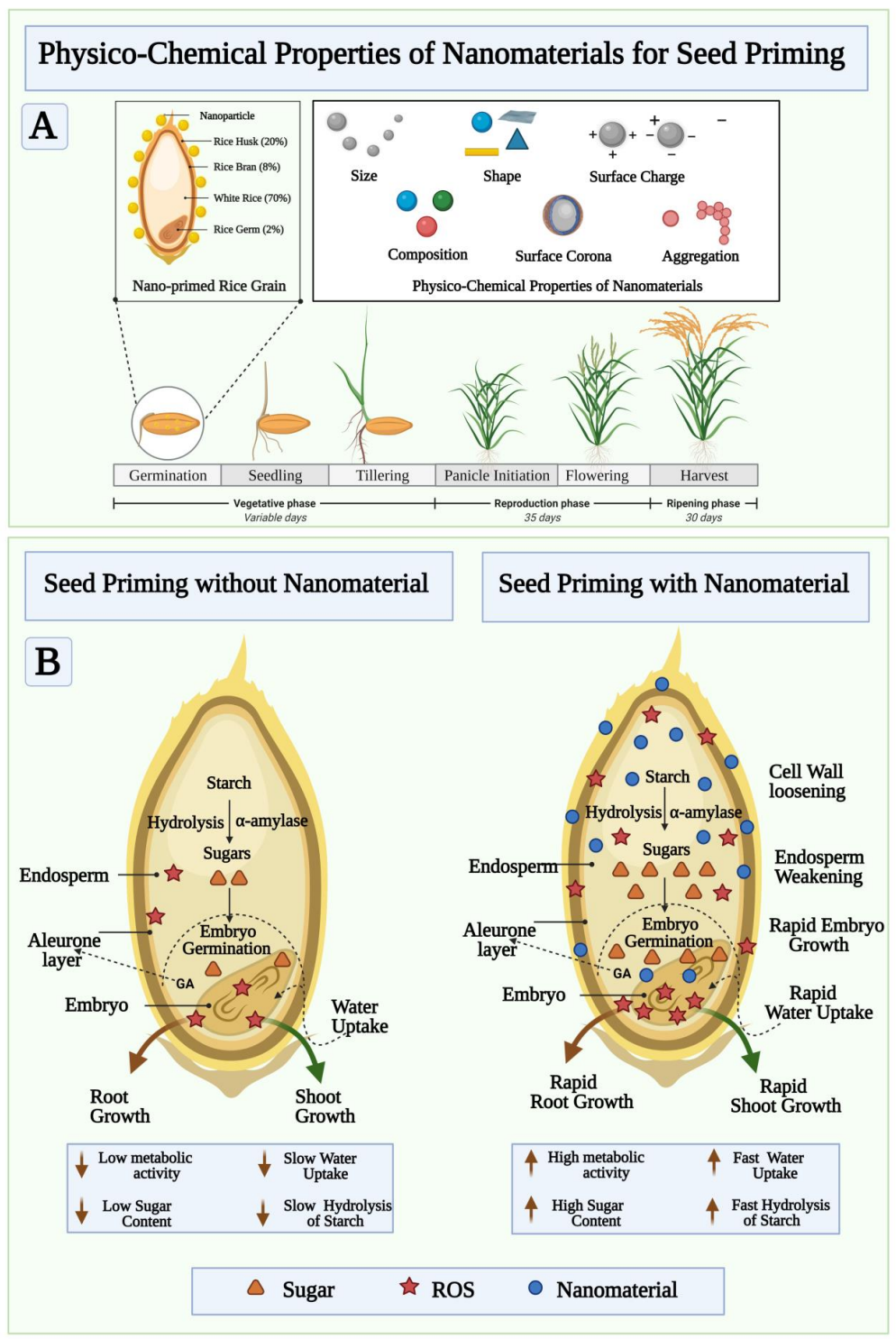

Figure 2. Physicochemical properties of nanomaterials influencing seed priming and its proposed mechanism. (A) The nanomaterial's size, shape, and surface chemistry make them a versatile candidate to modulate the seed priming phenomena via size-mediated diffusions and relocating to specific regions of the seed to activate synergistic mechanisms resulting in germination. (B) The versatile catalytic function of NMs selectively play role in promoting enzymatic and biochemical pathways to promote root/shoot growth. 


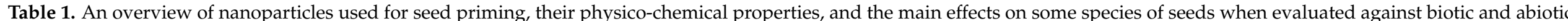
stress [7].

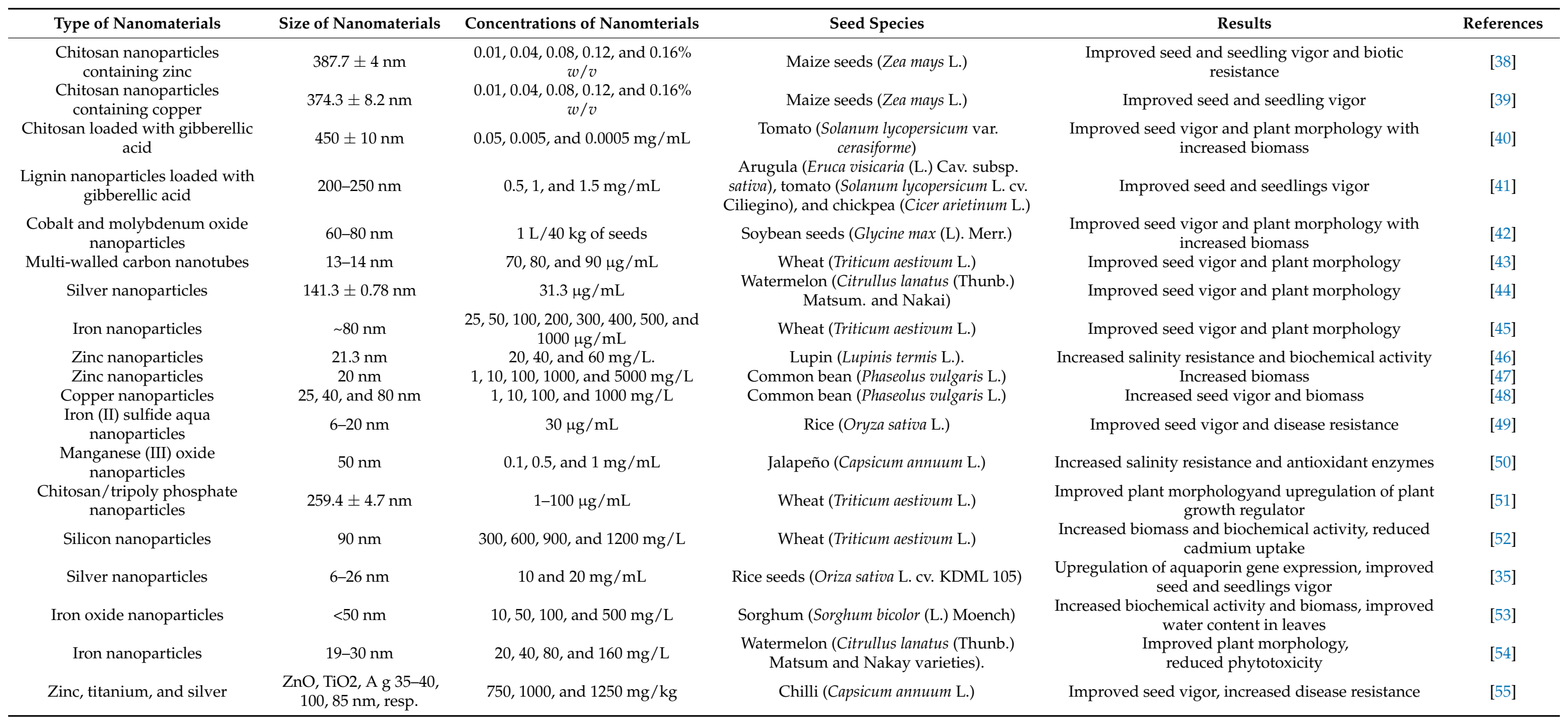




\section{Molecular Targets to Seed Nanopriming}

An analysis of the studies shows that the benefits of nanomaterial in promoting seed germination include (a) developing nanopores in the seed coat, (b) introducing reactive oxygen species (ROS) to the seed, and (c) using the nanocatalyst to boost enzyme activity at the starch-degrading site (Schematic Figure 2B) [35]. Although the exact mechanism behind seed nanopriming is not clearly understood, it appears that nanoparticles can induce physiological effects on seed germination. A nanomaterial that penetrates the seed coat and creates small pores can lead to increased water uptake and upregulation of aquaporin gene expression. Nano-pretreated seeds accumulate more ROS during germination than unprimed seed and other priming treatments, suggesting that significant ROS is needed to stimulate seed germination as shown schematically in Figure 2B. A study by Kibinza et al. demonstrated that osmo-priming sunflower seeds increases expression of a gene encoding catalase, suggesting that catalase may be a key enzyme responsible for the recovery of vigor in older seeds [56]. The enzyme superoxide dismutase scavenges $\mathrm{O}_{2} \bullet-$ and converts it into $\mathrm{H}_{2} \mathrm{O}_{2}$, and the enzyme catalase transforms $\mathrm{H}_{2} \mathrm{O}_{2}$ into water. A significant increase in antioxidant enzyme amounts could be the result of nanoparticle-mediated reduction of ROS. Due to the relationship between reactive oxygen species and antioxidant enzymes, seeds that are nanoprimed tend to contain a lot of antioxidant enzymes through nanoparticlemediated ROS mitigation. Furthermore, aquaporin and ROS-mediated interactions have been found to influence seed development [57]. The activation of seed germination could be achieved through aquaporins and ROS. Several studies suggest that aquaporins facilitate the transfer of $\mathrm{H}_{2} \mathrm{O}_{2}$ and $\mathrm{ROS}$ through biological membranes as well as water uptake [58]. As a result of the nanopriming process, nanopores are formed, allowing rapid influx of water into the seeds, and aquaporin genes are activated. For seed growth and germination to occur, seed antioxidant systems must regulate ROS in order to trigger oxidative signaling molecules to function. The nanopriming process leads to increased soluble sugar levels. Sugar concentrations in the cells can reduce osmotic potential, which reduces the water potential. In this way, the difference (gradient) between the water potential outside and inside the tissues increases, facilitating water movement into the seeds. Nanoprimed seeds have increased soluble sugars content, resulting in the increase of amylase activity, which leads to an increase in water uptake in the seeds due to the change in internal osmotic potential due to the increase of soluble sugars (solutes). Studies have demonstrated that $\mathrm{ROS}$, including $\mathrm{OH}$, contribute to radiation growth, cellular reorganization, and endosperm and testicular wasting [59]. Nanoparticles can generate ROS by triggering the formation of $\bullet \mathrm{OH}$. A theory suggests that during the short period of time (i.e., $24 \mathrm{~h}$ ) spent soaking seeds in nanopriming solutions, the $\mathrm{OH}$ produced by bound nanoparticles would facilitate a process of loosened cell walls, which would stimulate the growth of seedlings [60]. As a nanocatalyst, nanoparticles absorbed from the seeds may be crucial in accelerating the reaction rate of starch hydrolysis catalyzed by $\alpha$-amylase. (Figure 2B) [35]. A recent study showed that nanoparticles can act as nanocatalysts, and that soluble starch can be rapidly digested with nanosilver [61]. As reported by Mahakham et al. [35] the aquaporin gene (PIP1;1 and PIP2;1) expressed higher levels in rice seeds primed with silver nanoparticles. In conjunction with triggering the expression of aquaporin genes, aquaporins (water channels) are trans membrane proteins that facilitate the movement of water and metabolic gases across biological membranes, and regulate water homeostasis. Nanopriming of rice seeds is an efficient method for boosting their starch metabolism. The hydrolytic enzyme $\alpha$-amylase converts reserved carbohydrates into soluble sugars during seed germination, which keeps the respiration metabolism active until sufficient photosynthesis occurs. A study conducted by Jing et al. [62] examined the transcriptomes of cotton seeds treated with poly(acrylic acid)-coated cerium oxide nanoparticles (PNCs) and then exposed to saline stress. Compared to unexposed control groups, ROS are accumulated under conditions of salinity stress. When salinity stress is applied to nanoprimed seed, the expression of 13 genes related to ROS signaling pathways and 10 genes related to ion homeostasis was detected. Plants produce antioxidant enzymes to counteract oxidative damage, including 
peroxidases (POD), glutathione S-transferases (GST), and peroxiredoxins (PRX). Comparing seedlings under salt stress, POD and GST were significantly up regulated, while PRX was down regulated by PNC priming. A PNC priming also increases magnesium levels in cotton roots, as well as genes (CAD1 and TPS) with functions related to terpene synthase. In response to salt stress, PNC seed priming regulates cotton seedling development through signaling ion and antioxidant pathways. Among the oomycete species investigated in the study, Siddaiah et al. [63] found that chitosan nanoparticles showed antimicrobial activity against Sclerospora graminicola, which causes downy mildew. By priming seeds with chitosan nanoparticles, plants display improved immunity, with increased gene expression of alkaline peroxidase, polyphenoloxidase, and phenylalanine ammonia lyase. The nanochitosan seed priming over expression involves PR1 and PR5, which are involved in the salicylic acid pathways. Using zinc oxide nanoparticles to combat environmental stress factors was studied by Chaudhary et al. [38]. In response to $\mathrm{ZnO}$ nanopriming, miR156 and miR159 expression increased, which plays a significant role in helping plants resist biotic and abiotic stresses. A study by Ye et al. [50] demonstrated that manganese nanoparticles improved seedling growth under salinity conditions. Nanopriming with manganese upregulated SOD (superoxide dismutase), which offers protection against ROS damage and prevents phytotoxicity. It is possible that nanoparticles are present within the seed to account for this behavior. Nanoparticles appear to enhance starch hydrolysis, but the exact mechanism is still unclear [64]. Nevertheless, further research is warranted to determine the exact mechanism.

\section{Effects of Seed Nanopriming under Abiotic and Biotic Stresses}

Abiotic and biotic stresses cause damage to seed growth and eventually lead to economic losses. In the wake of global warming and climate change, seeds are subject to an increased number of biotic and abiotic stress combinations, which negatively affect their growth and yield [65]. The simultaneous presence of abiotic stress factors such as drought, flood, salinity, heavy mineral contamination, cold and heat has been shown to severely deter seed germination (Figure 3A). The biotic stress that is exhibited in Figure 3B includes a variety of plant pathogens including bacteria, fungi, viruses, nematodes, insects, and others. As a result of pathogen infection, changes in plant physiology often result in reduced biomass, early flowering, decreased seed set, accumulation of protective metabolites, and many other changes [66]. Researchers have reported that a variety of nanomaterials reduce biotic and abiotic stress and improve seed germination $[67,68]$.

\subsection{Abiotic Stress Ameliorating Nanomaterials}

By seed priming with cerium oxide nanoparticles, An et al. studied the molecular mechanisms behind plant salinity stress tolerance. Poly (acrylic acid)-coated cerium oxide nanoparticles (PNC) show morphological, physiological, biochemical, and transcriptomic effects on cotton seedling priming under salinity stress, according to An et al. An advantage of PNC nanoparticle seed priming is that it can be used to increase a crop tolerance to stress during the early seedling stage in a sustainable, practical, and scalable way. These results showed promising molecular mechanisms that could be synergistically operated to enhance plant salt tolerance [62]. According to a recent study published by Baz et al., nanopriming with water-soluble carbon nanoparticles (CNPs) significantly increases seed vigor and seedling growth of lettuce under salinity stress. Under high temperatures and salinity stress, CNPs have been shown to significantly promote seed germination. A CNPassisted nanopriming treatment enhanced lateral root growth but slightly inhibited the elongation of primary roots, resulting in a balanced accumulation of chlorophyll in high salinity stress [69]. The effects of manganese (III) oxide nanoparticles (MnNPs) on the salinity stress of capsicum annum $L$ were studied by Ye et al. It showed that MnNPs can penetrate seed coats and form corona complexes. The results of the study demonstrate that MnNPs can modulate biochemical interactions in seeds that exhibit salinity tolerance in order to promote sustainable agriculture [50]. The study showed that nano-silica primed 
zea mays seeds had a higher rate of germination and a higher seedling vigor index. The priming process helps to increase the activity of antioxidant enzymes, which can suppress lipid peroxidation by suppressing the production of ROS under salinity stress. Additionally, priming reduces abscisic acid content while increasing gibberellin content. As a result of this hormonal balance, the hydrolysis enzymes (amylase and lipase) are activated. It was found that nano-silica priming enhanced the metabolic activity of maize seeds when exposed to salinity [70]. Khan et al. investigated the effect of nano $\mathrm{ZnO}$ and nano Fe on cadmium accumulation in wheat. Nanoprimed seeds show increased length of spikes, shoots, and roots, as well as increased grain size. Superoxide dismutase activity and electrolyte leakage were reduced in nanoprimed seeds. Nanoparticles in seeds increase wheat biomass and nutrient content as well as decreasing Cd toxicity overall [71]. The role of bulk and nanosized $\mathrm{SiO}_{2}$ particles in fenugreek germination has been investigated by R. Ivani et al. A study concluded nanosized particles of $\mathrm{SiO}_{2}$ protect fenugreek seeds from salt stress and improve growth attributes [72]. A study by S. Hojjat et al. examined the effects of silver nanoparticles on the germination of fenugreek seeds under salinity conditions. AgNPs improved salinity tolerance in fenugreek seedlings. This may increase various plant defense mechanisms that reduce salt stress [73]. In a study by Konate et al., magnetic $\left(\mathrm{Fe}_{3} \mathrm{O}_{4}\right)$ nanoparticles were shown to mitigate heavy metals uptake and toxicity in wheat seedlings. Physiological mechanisms were investigated in wheat seedlings to determine how magnetic nanoparticles (nano- $\mathrm{Fe}_{3} \mathrm{O}_{4}$ ) mitigated the toxic effects of heavy metals (Pb, $\mathrm{Zn}, \mathrm{Cd}$, and $\mathrm{Cu})$ [74].

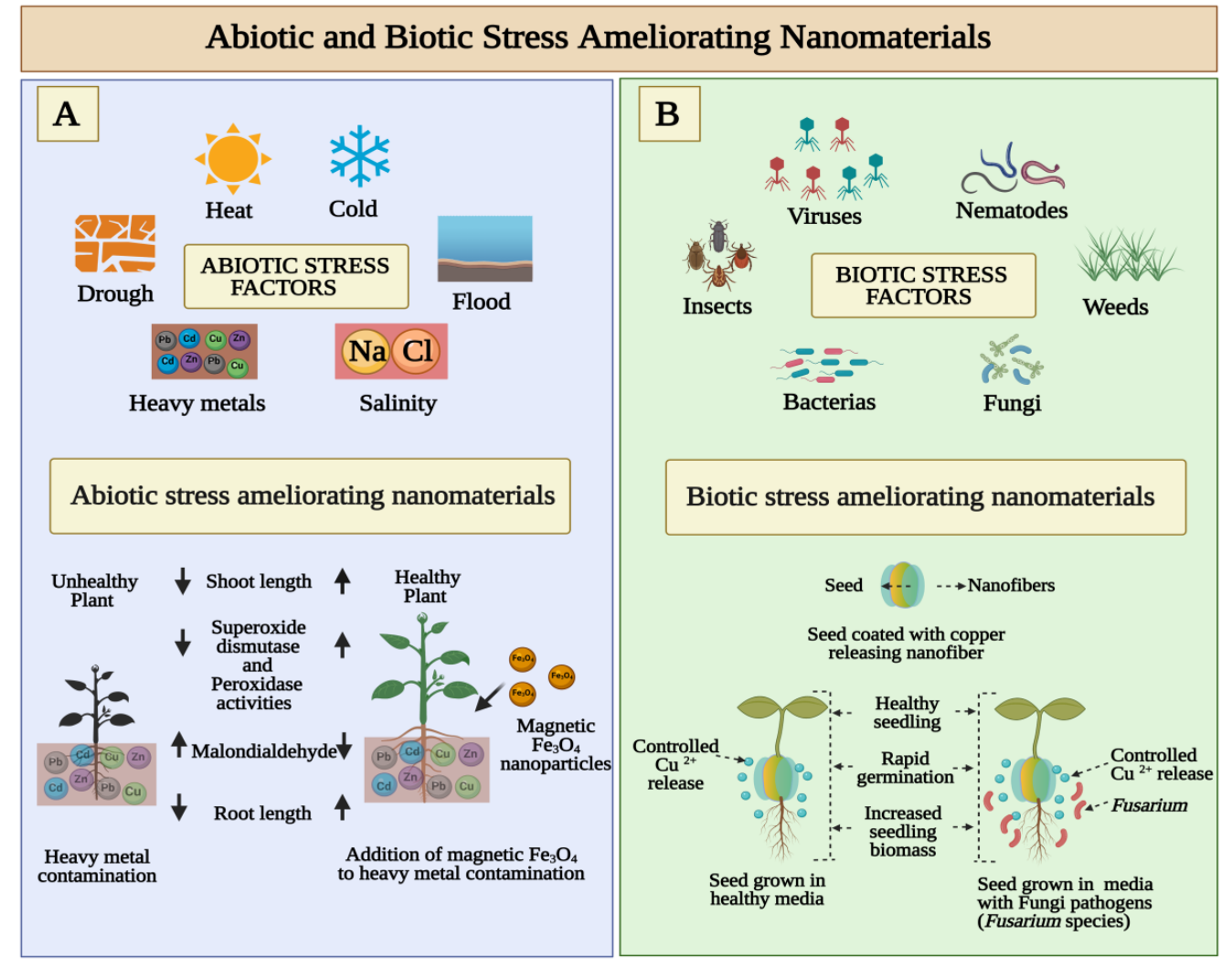

Figure 3. Effect of nanopriming agents to improve seed germination in abiotic and biotic stress conditions. (A) Environmental conditions in combination with soil quality may pose stress to different phases of seed germination affecting biochemical pathways involved in the root-shoot development. The metal chelators and biocatalytic NPs could play a rescue role mitigating those abiotic conditions, giving a healthy plant development. (B) Seed nanopriming with broad spectrum NMs with known microbicidal and anti-parasitic effect improve seed germination in biotic stress conditions boosting overall crop yield. 


\subsection{Biotic Stress Ameliorating Nanomaterials}

As a bioprotectant against rice borne pathogens P. grisea and X. oryzae, Sathayabama and Muthukumar investigated the antimicrobial activity of chitosan guar nanoparticles (CGNP). The treated rice showed no symptoms of blast disease. Rice plants with CGNPapplied antimicrobial protection displayed an enhanced rate of seed germination and growth [75]. T. Xu et al. demonstrated enhanced seedling development and agrochemical delivery by biodegradable, biopolymer-based nanofiber seed coatings. The germination and subsequent growth of nanofiber-coated tomato and lettuce seeds were studied in a greenhouse, with and without a fungal pathogen (Fusarium species) as shown in Figure 2B. Based on recent observations, it appears to be possible to use nanomaterials to deliver active ingredients at precise locations. Nanofiber seed coatings provide precise agrochemical delivery and significantly improve seedling germination and biomass in comparison to conventional film coating techniques used in the industry due to their nanofibrous structure and controlled release kinetics [76]. The effects of cinnamaldehyde encapsulated mesoporous silica nanoparticles (MSNP) on seed borne diseases were studied by Bravo Cadena et al. Based on the results of this study, it is clear that MSNP significantly enhanced the antimicrobial activity of plant products, which allows the use of volatile biocides such as essential oils at very low concentrations to prevent microbial diseases in crop plants [77]. Choudhary et al. evaluated the effect of zinc chitosan nanoparticles as a seed priming agent and foliar application to maize plants. An in vitro study showed that seed nanopriming with Zn-chitosan nanoparticles enhanced seed germination and inhibited fungal growth. These results showed that $\mathrm{Zn}$-chitosan nanoparticles have strong fungicidal activity, are an effective micronutrient fortifier, and could stimulate maize crop growth [38].

\section{Effect of Combined Seed Priming Treatment of Nanomaterials with Microbes}

Seed germination and seedling growth characteristics of several plant species have been enhanced by nanopriming with a variety of nanomaterials $[9,44]$. Several studies on the interaction between nanomaterials and plant-benefitting bacteria, called Plant GrowthPromoting Rhizobacteria (PGPR), have been identified as a novel approach in sustainable agriculture [78]. Through the application of both PGPR and nanomaterials, plants may be able to resist environmental stress through several physiological and morphological mechanisms, such as improved root system nutrient uptake and induced expression of cellular antioxidative enzymes [79]. By using silicon nanoparticles as a seed priming agent, Mahakham et al. studied the role of silicon nanoparticles in the cell growth process. This study examined the effect of silicon nanoparticle-mediated seed priming on Pseudomonas species enhancing growth, physiology, and antioxidant metabolism in Melissa officinalis L. According to Figure 4, seed priming, pre-sowing, and seedling inoculation with bioelicitor improves plant growth and phytochemical constituents. Combined with silicon nanoparticles, $P$. fluorescens and P. putida significantly increased plant biomass indices, the relative water content of leaves, photosynthetic pigment values, essential oil yield, and all major components (except thymol). It has been found that seed priming with nanosilicon particles combined with inoculation with pseudomonas strains boosts the number of both primary and secondary metabolites in lemon balm plants [35]. Shcherbakova et al. demonstrated that pre-seed treatments with microbial inoculants and molybdenum (Mo) nanoparticles. The goal of this study was to determine the effects of pre-seed treatment with microbial inoculants and Mo nanoparticles on the composition of root exudates of chickpea plants and the diversity of microbes in the rhizosphere. Shcherbakova et al. examined the activity of enzymes involved in the antioxidant protection system and the formation of plant-microbial systems induced by nodules and rhizosphere bacteria as well as Mo nanoparticles before sowing seeds [80]. De Gregorio et al. investigated the application of beneficial rhizobacteria immobilized in nanofibers to bioinoculants soybean seeds. Their findings showed that inoculating seeds with PGPR provides soil with a significant number of beneficial microorganisms. A nanofiber-immobilized rhizobacteriacoated soybean seed was also evaluated for its influence on bacterial survival during 
seed storage and on characteristics of germination and plant growth. Seed coating with $P$. agglomerans improved germination, size, and weight of the roots. Moreover, seed coating with Bacillus californianus increased leaf number and dry weight. In view of this, the technique applied in the current study to prime seeds with nanofiber-immobilized PGPR could be regarded as a promising eco-friendly strategy to enhance soybean production by using microbial inoculants [81]. According to Taran et al., colloidal solutions of metals for micronutrients enhance plant health by enhancing resistance to exposure to unfavorable environmental conditions and enhancing plant nutrition by increasing the penetration of nanoscale elements in the cell walls. Combining seed treatment with colloidal solution of Mo nanoparticles and microbial preparation results in a four-fold increase in nodule formation compared to control plants [82].

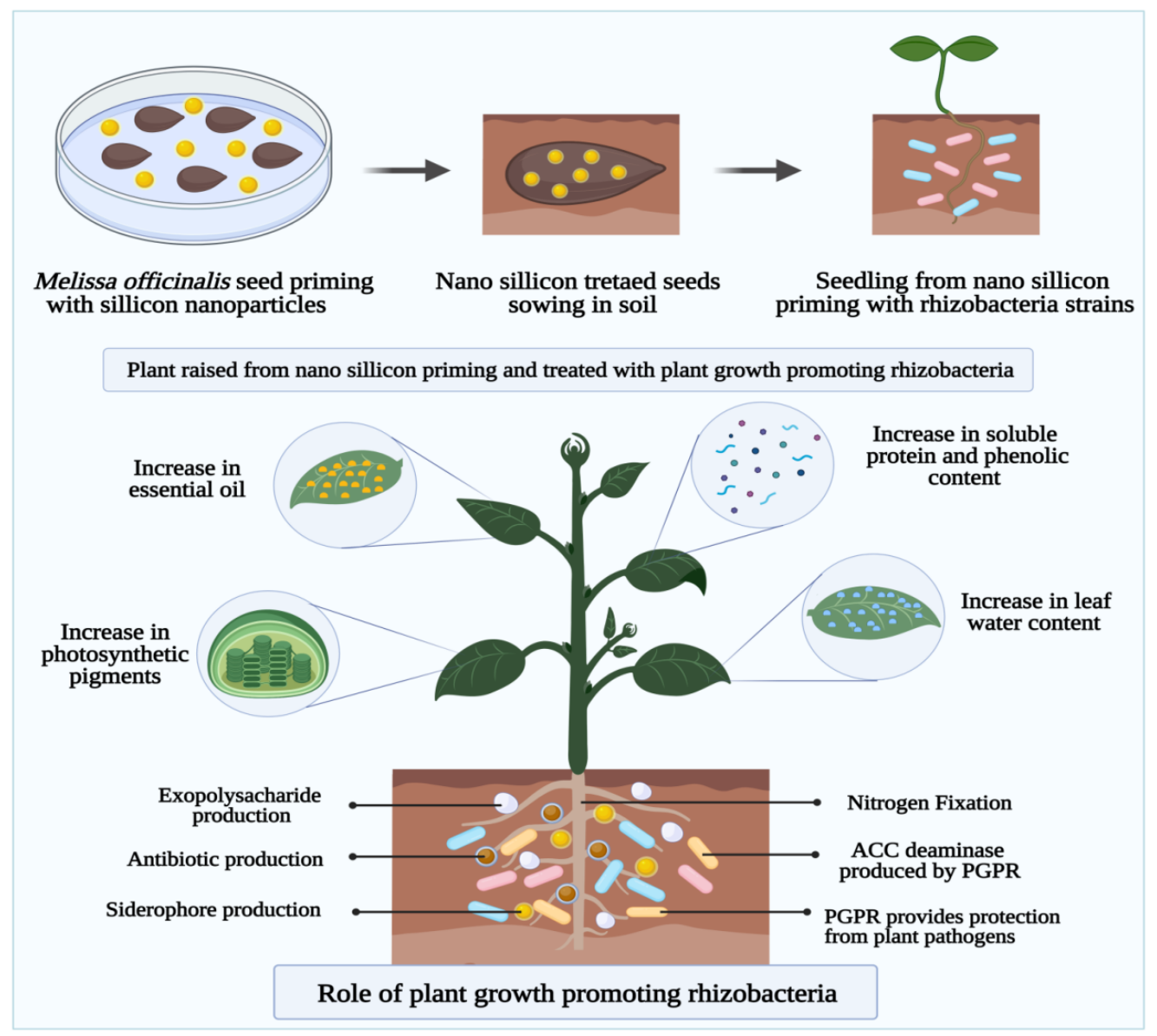

Figure 4. The plant growth-promoting rhizobacteria (PGPR) combined seed nanopriming treatment with a selection of microbicidal nanomaterials without influencing the PGPR spares beneficial microbes of the soil and plant tissues. This promotes $\mathrm{N}_{2}$-fixation improves harvest quality and yield via selectively increasing threshold towards biotic stresses.

\section{Effect of Combined Seed Priming Treatment of Nanoparticles and Cold Plasma Technology}

The combined potential benefits of working with cold plasma and metal-based nanoparticles seed priming are rarely studied. The reactive oxygen and nitrogen species (ROS and RNS) are important signaling molecules that are involved in seed signaling pathways, cellular physiology, gene expression, differentiation, and growth [83]. Seed treatment with cold plasma and nanomaterials is an eco-agricultural high-tech technique that can increase crop yields $[84,85]$. The non-ionizing low-level radiation activates the vitality of a seed without causing gene mutation, so there is no genetic risk. A new path to increasing grain yield is provided by the application of cold plasma and nanotechnology in agricul- 
ture, since it is a fast, cheap, green, and riskless method [86]. Using cold plasma could help increase germination rates and peroxidase activities in seeds [87]. Figure 5 illustrates that both UV and biologically active agents (nitrogen and oxygen active species) produce molecular changes in seeds which then influence food composition [88]. In a study, Abedi et al. reported that seed priming with cold plasma enhanced early growth and flowering while protecting Cichorium intybus with selenium nanoparticles. This study provides a better understanding of the potential advantages of cold plasma in improving early growth, protection, and production. Figure 6 indicate that plasma with nano-selenium is capable of improving plant tolerance to stress conditions via activation of plant defense systems, especially antioxidants. As a result, plasma priming combined with nano-Selenium at a low dose is an effective approach to promote plant growth, biochemistry, and protection [89].

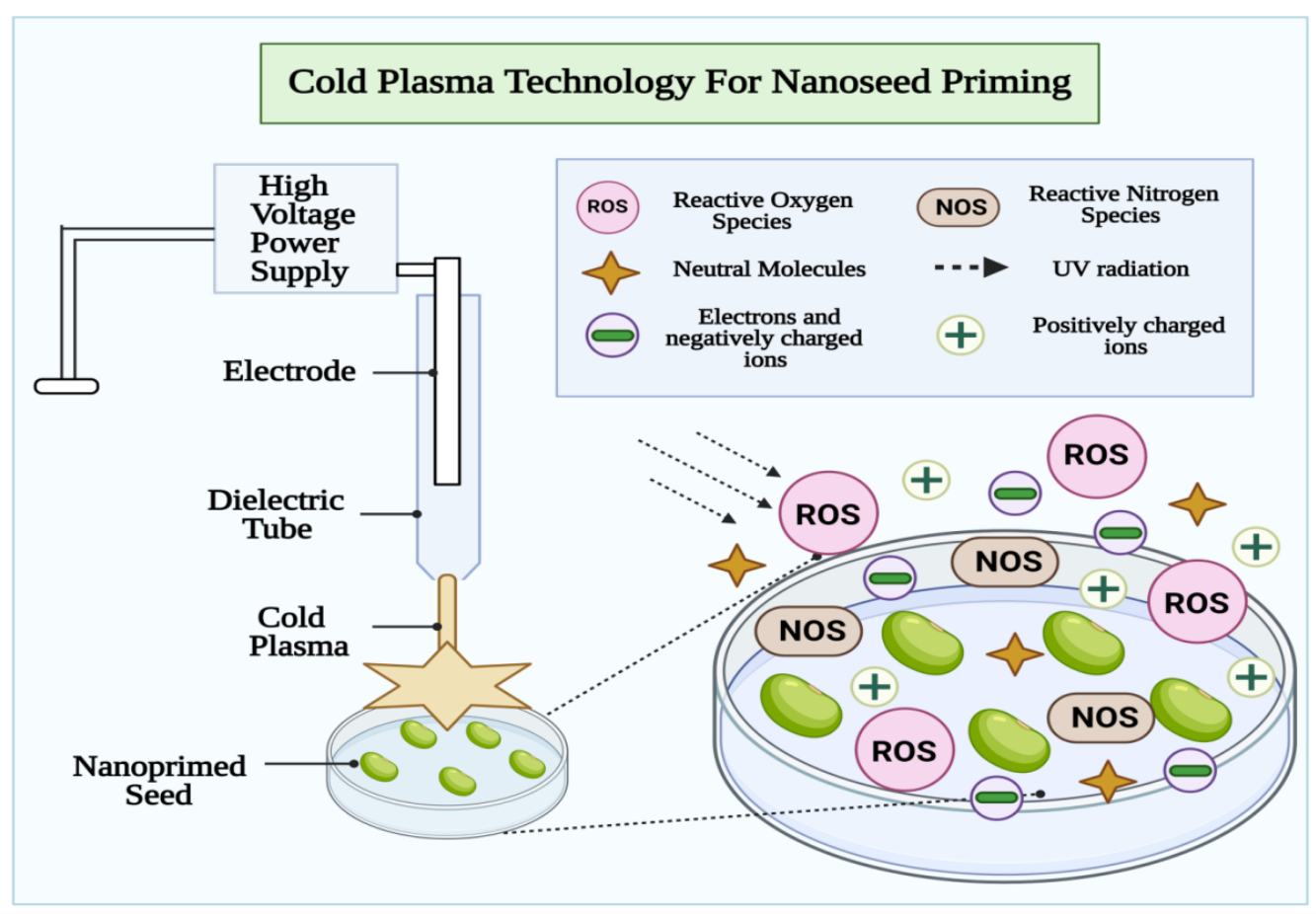

Figure 5. The cold plasma (dielectric barrier discharge) mediated seed priming improve seed vigor via synergistical activation of plant defense machinery against ROS, supporting redox homeostasis in plant. Bases on cold vs. non-thermal plasma used in seed priming, the energetic electrons, charged particle, and reactive species are produced, which dissolve tough seed coat promoting water uptake and drought yield in the crop.

Using non-thermal plasma, A. Babajani et al. studied selenium and zinc oxide nanoparticle reactions of seed priming. Medicinal plant Melissa officinalis has shown to respond differently to zinc oxide (nZnO) and selenium (nSe) nanoparticles when primed with cold plasma. The primed seeds with plasma were cultured in nutrient solution modulated with nSe and nZnO. As a result of plasma priming, the growth-related characteristics (stem length, root length, and width of the leaf) as well as biomass accumulation were improved, as well as the toxicity signs of nSe were attenuated [88]. The study described differential physiology and expression of phenylalanine ammonia lyase (PAL) and universal stress protein (USP) in endangered species published by Moghanloo et al. (2019). Treatments with plasma and nano silicon (nSi) simultaneously had the highest expression rates of the gene for phenylalanine ammonia lyase. In contrast, the plasma treatments did not make a significant difference in the expression of USP gene, but nSi-treated seedlings exhibited higher levels of USP expression. After plasma and nSi were applied, leaf thickness and vascular tissue development were reinforced (xylem and phloem). In the present study, nSi and plasma as potential antagonists of phytotoxicity are described, which may be 
used as a theoretical base for possible commercialization [90]. Cold plasma has been reported to reduce the toxicity signs of nano zinc oxide in capsicum cayenne by modifying growth, differentiation, and physiology, according to A. Iranbakhsh et al. In this study, the systemically applied cold plasma solution and zinc oxide nanoparticles $(\mathrm{nZnO})$ were evaluated within plant (Capsicum annuum) under in vitro and in pot conditions using a functional scientific device and metal-based nanoparticles. Eliciting peroxidase enzyme activity in both culture media was achieved by treating either with plasma or $\mathrm{nZnO}$ on both roots, and it was found that plasma activity and/or nZnO activity of phenylalanine ammonia-lyase were significantly greater. Plant growth was most influenced by soaking seeds with nanomaterials before plasma treatment in the pot experiment [91].

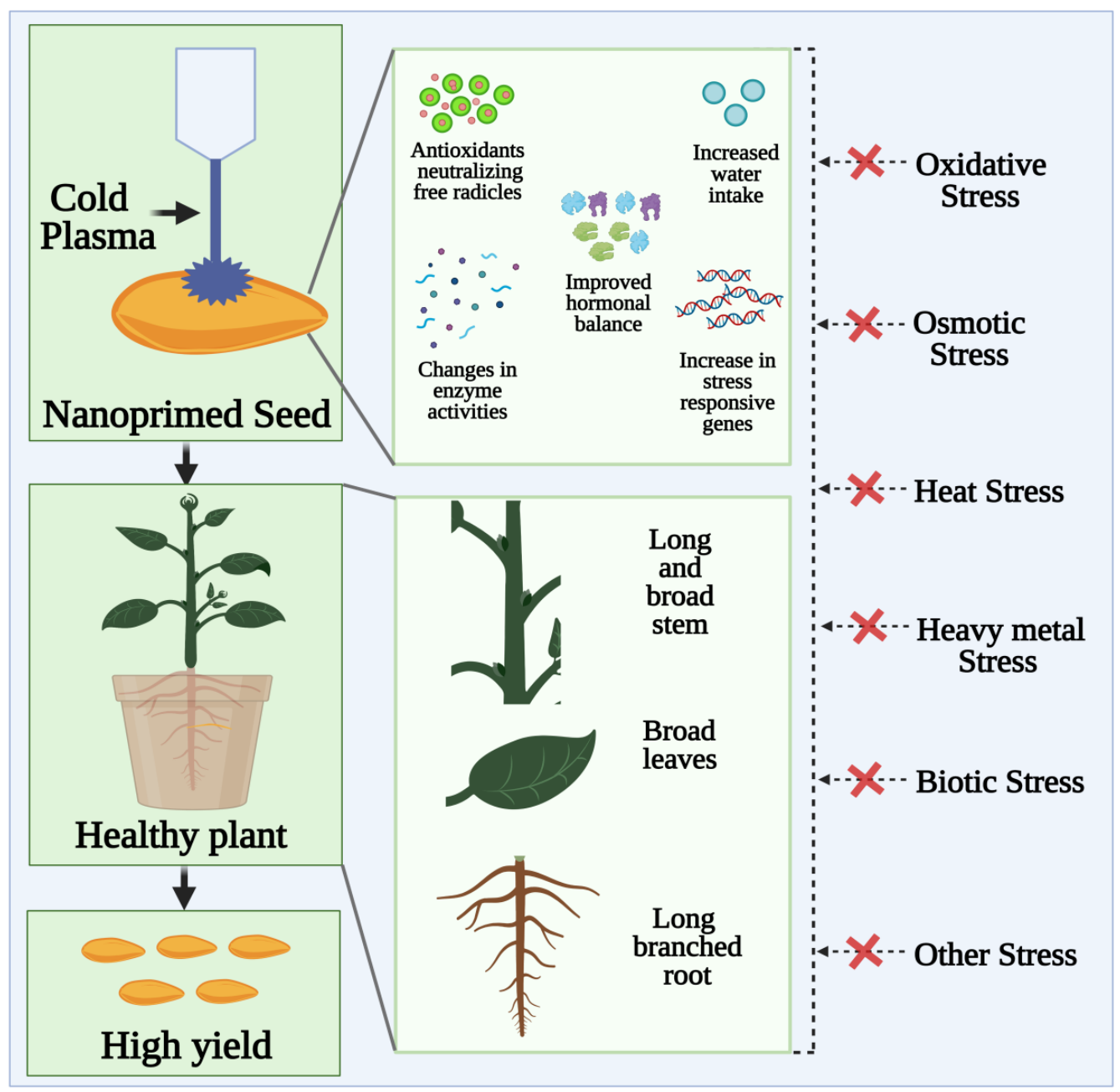

Figure 6. As an alternative to ecotoxic chemical treatments, non-thermal and cold plasma-based seed nanopriming has advantages in managing environmental stressors towards improving seed vigor and enhancing seed germination. The enhanced antioxidant system and activated defense response towards improved physiological processes; seed scarification and pathogen inactivation via plasma affects seed surface environment ameliorating improved features at molecular level and leave/root/shoot proportions.

\section{Artificial Intelligence and Machine Learning Technology for Nanoprimed Seed Diagnostics}

Seeds with better seed germination and seedling emergence rates can ensure reliable emergence under a variety of agricultural conditions and are therefore instrumental in ensuring yield potential and uniformity. As of today, germination scoring is typically done by human observation, and therefore, has a limited frequency, scale, and accuracy. 
In order to handle this bottleneck, many attempts have been made to automate both seed diagnostics and associated phenotypic analysis, with more than one research-based solution such as germinator, phenoSeeder, and the MultiSense tool as a result [92]. As shown in Figure 7B, by using these softwares, post seed nanopriming diagnosis can be done to predict nanoprimed seeds viability and phenotypic analysis.

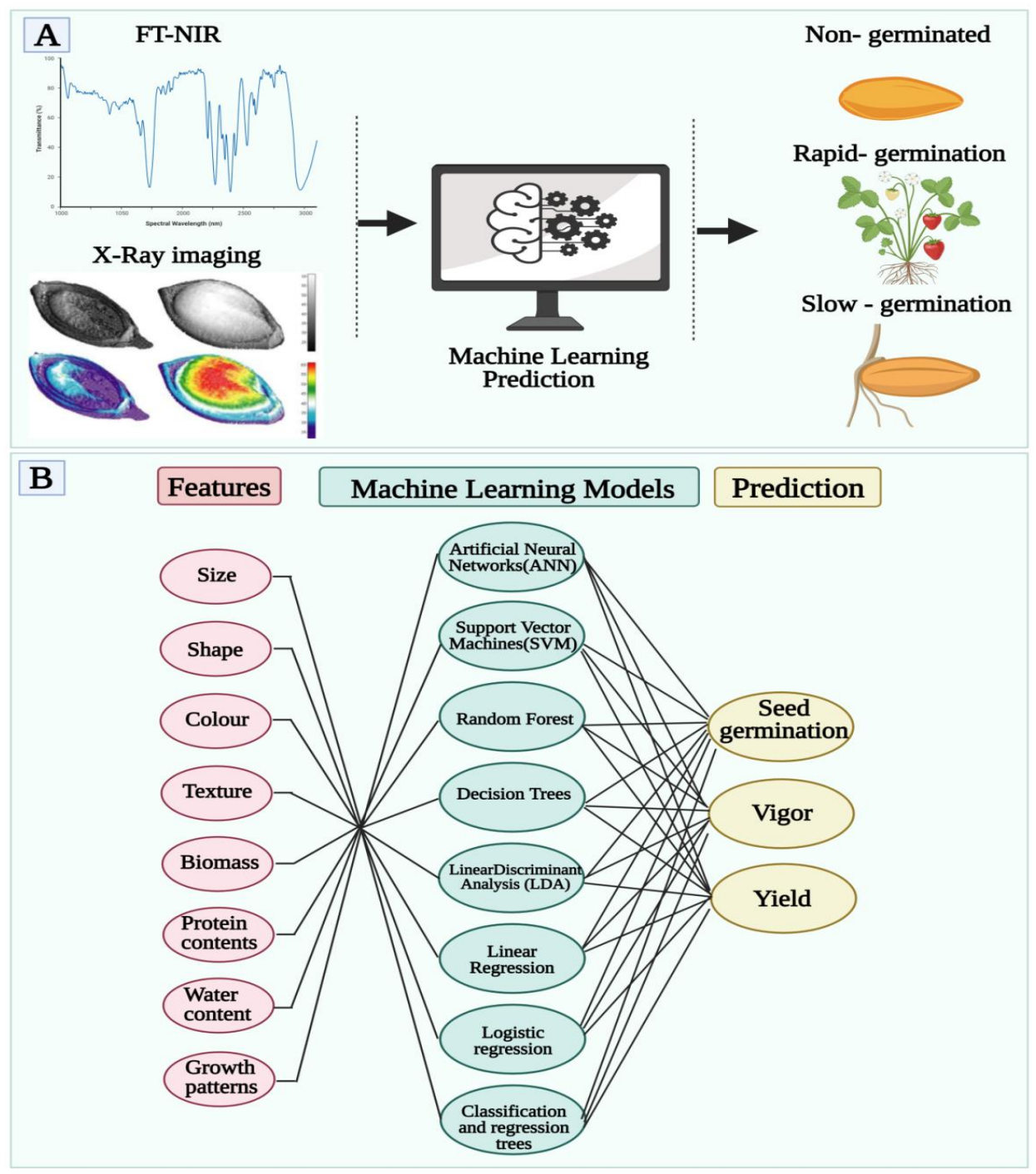

Figure 7. (A) Artificial intelligence and machine learning may assist with infrared spectroscopy and X-ray image data mining and curation. AI and ML may further complement via optimizing seed priming technology based on chemianalytic profiling for heat and moisture content assisting in breaking seed dormancy. (B) Post nanopriming, AI and ML tools can be used to predict seed germination, vigor, and yield of nanoprimed seeds.

Recently, advanced computer vision and machine learning methods have been applied to germination assays; among them, the Rice Seed Germination Evaluation System which uses artificial neural networks to gauge the germination status of Thai rice species [93]. Numerous computer vision and machine learning that combined analytic methods have been developed to automate phenotypic analyses of organs as diverse as leaves, roots, and reproductive organs [94,95]. Nanoprimed seed germination can be measured dynamically and objectively based on the color, texture, morphology, and growth pattern of a seed, thus enabling new biological findings about seed physiology. In addition, the automation of seed germination scoring represents an excellent opportunity to start standardizing seed science research. The quality of seeds and their vigor can be accessed through digital 
analysis, but also biological experiments under varying conditions can be quantitatively compared to increase the confidence of research results. A study by Genze et al. presented accurate germination detection, prediction and quality assessment based on machine learning [96]. Several attempts have been made to automate seed testing in order to reduce the number of error-prone manual steps required in this process. Various analyses of seeds have recently been carried out using modern image analysis techniques since they are easily automatized and can provide unbiased and quantitative measurements which are error-free [97]. Modern convolutional networks were used in the present study to detect individual seeds and to distinguish germinated from non-germinated seeds with higher precision. By using artificial intelligence to measure germination potential, the evaluation process could be sped up. Compared to manual methods and conventional methods, it has a lower error rate and a higher performance. This allows it to provide more accurate germination indices and assess the quality of seeds. An approach for determining seed quality was developed using FT-NIR spectroscopy and X-ray imaging data by A D Medeiros et al. [98]. The results shown in Figure 7A illustrate how FT-NIR and X-ray imaging can be used in conjunction with machine learning algorithms to improve seed germination and vigor prediction. This study examines the use of FT-NIR spectroscopy in conjunction with X-ray imaging in the prediction of seed quality traits (germination and vigor). Seed germination capacity can be accurately measured ( $85 \%$ accuracy) using the proposed approach. A machine learning algorithm developed using both NIR spectra and X-ray images can easily, efficiently, and accurately predict seed germination. A D Medeiros et al. developed a system for classifying soybean seedlings based on quality data [98]. In this study, it was proposed to use traditional machine learning methods for determining the size, shape, and physiological potential of soybean seeds and seedlings. The models were developed using free and low-cost software based on images of soy seeds and seedlings. Using the developed model for seed and seedling classifications, $94 \%$ of seed and seedlings were accurately classified. By using interactive and traditional machine learning models, high precision was demonstrated in the models developed, which were able to classify soybean seeds by their appearance, as well as beans and their seedlings by vigor quickly and non-subjectively. A deep learning architecture is an artificial neural network (ANN) that is used to find patterns in data or model complex relationships between inputs and outputs. Classifiers are based on multilayer neural networks for identifying wheat grain (seed) irregularities grown in a variety of agricultural environmental zones. The scientific and technological developments of agricultural enterprises enable them to generate a large amount of data. Automated analysis methods are needed to process this data size. It is a very useful way to support agricultural center experts using advanced computing techniques $[99,100]$. Combined with real-time processing of data, it helps farmers take correct decisions concerning harvesting crops, planting, and fertilization. The following Table 2 displays some examples of seed analysis software with their features for possible use to diagnose nanoprimed seeds. 
Table 2. Software that processes images simultaneously and produces accurate analyses of seedling germination and establishment. Using artificial neural networks, advanced computer-vision and machine-learning techniques have been applied to germination assays to assess the germination status of various nanoprimed seed.

\begin{tabular}{|c|c|c|c|c|}
\hline $\begin{array}{l}\text { Seed Analysis } \\
\text { Software }\end{array}$ & Type of Seed Studied & Feature & Remark & Reference \\
\hline Germinator & Arabidopsis thaliana seed & An indicator of germination & $\begin{array}{l}\text { An automated } \\
\text { high-throughput evaluation } \\
\text { procedure for germination }\end{array}$ & [101] \\
\hline $\begin{array}{l}\text { Seed Vigor Imaging } \\
\text { System }\end{array}$ & $\begin{array}{l}\text { Soybean and } \\
\text { Corn Seed }\end{array}$ & $\begin{array}{l}\text { Used to calculate the length } \\
\text { of seeds }\end{array}$ & $\begin{array}{c}\text { Physiological differences } \\
\text { between seed lots could be } \\
\text { identified }\end{array}$ & [102] \\
\hline SeedUSoon & - & $\begin{array}{c}\text { Tracking of different } \\
\text { mutations }\end{array}$ & $\begin{array}{l}\text { It provides a visual } \\
\text { representation of the genetic } \\
\text { link between related seed } \\
\text { batche }\end{array}$ & [103] \\
\hline SmartGrain & Arabidopsis thaliana seed & Recognize varieties of seeds & $\begin{array}{l}\text { Understanding the genes } \\
\text { and mechanisms of grain or } \\
\text { seed size and shape }\end{array}$ & [104] \\
\hline SeedExtractor & Rice seeds & $\begin{array}{l}\text { Measures seed size, shape } \\
\text { (including length, width, } \\
\text { circle and color }\end{array}$ & $\begin{array}{l}\text { Crop yield traits can be } \\
\text { determined }\end{array}$ & [105] \\
\hline SeedCounter & Wheat grain & $\begin{array}{l}\text { The use of a mobile device } \\
\text { can be used to estimate the } \\
\text { number and size of grains }\end{array}$ & $\begin{array}{l}\text { It is possible to improve the } \\
\text { accuracy of seed analysis. }\end{array}$ & [106] \\
\hline
\end{tabular}

\section{Limitations of Nanopriming Techniques and Future Prospects}

It is recognized that despite remarkable progress, scientists do not have a complete understanding of how these nanomaterials can affect the macro- and micro-environments of seeds. It is alarming that there is still a lack of basic understanding regarding the possible health and safety effects of engineered nanomaterials on both human and nonhuman receptors considering the actual and projected levels of exposure [107]. A general rule concerning seed nanopriming does not exist, and there is no clear trend regarding priming responses depending on the taxonomic position of the species. As a result of some nanopriming treatments, there is a possibility of contamination of the medium with fungi and bacteria, which may greatly hinder subsequent seed germination [7]. A seed that has been nanoprimed is dried back to its original moisture content, but this process is done faster than the dehydration of mature seeds. Several researchers have hypothesized that brutal desiccation procedures alter the effects of nanopriming [7]. As a consequence, nanoprimed seed material can be less stable, and higher maintenance costs for seed companies and farmers are consequently incurred. In some cases, repeated nanopriming treatments can partly prevent seed viability losses, whereas in others, such losses are permanent and cannot be reversed [108]. Possibly requiring an additional treatment may be both an extra cost and a source of variability because germination potential may not be fully restored.

Nanopriming can be a potential future target for sustainable agriculture with the current global supply versus demand trend. A fortification program consists of adding vitamins and minerals to processed foods as a public health measure to improve the nutritional quality of the food supply. The goal is to enhance the nutrient intake by the population [52]. As a result, biofortification reduces the runoff of fertilizers and other agrochemicals and their inputs into the environment. As a result of seed biofortification, stands have been established and plant production, yields, nutrient content, and water utilization have increased as well as plant tolerance to biotic and abiotic stresses have increased [109]. The technique has been found to be a simple, practical, and cost-effective approach to improving the quality of seed and crops in resource-constrained regions. Compared to conventional seed priming, seed priming using engineered nanomaterial 
produced higher germination rates at equivalent or lower life cycle embodied energy. Nanotechnology is also an exceptionally potent way to deliver nutrients effectively due to its ability to deliver a wide range of engineered nanomaterials in a more efficient manner than before $[34,110]$. By introducing nano-bio-fortification into seeds, less fertilizer potentially may be consumed. This results in the need to use less water and less resources to cultivate the same volume of nutrient-rich food. Nano-bio fortification of seeds could also assist in shortening the growth cycle of plants (e.g., requiring less time for them to germinate and to mature), allowing the land to grow crops faster in the future. In similar ways to other agronomic methods, the success of seed nano-biofortification will depend on how well it is adapted to the setting, including the type of soil, the type of crop and the climate, and the location [111]. The advantages of nanotechnology need to be compared to other biofortification procedures that may provide long-term and cost-effective solutions, including plant breeding and CRISPR/transgenic technology [111]. In addition to assessing the overall environmental implications, it is important to determine if nano-based solutions are practical compared to conventional practices [112]. Nanomaterials continue to be manufactured in larger scales, which lead to further decreases in production costs. It is highly likely that nanotechnology will integrate with seed biofortification practices in the future, especially as highly specialized and tunable nanomaterials emerge. Nano-enabled seed biofortification is an important topic that merits intense scrutiny and greater attention given its potential benefits and the increasing global food insecurity that we will face in the coming decades.

Author Contributions: Conceptualization, A.S. (Amruta Shelar), A.V.S. and R.P.; data curation, A.S. (Amruta Shelar), A.S. (Akanksha Shelar), S.P.S. and A.V.S.; writing-original draft preparation, A.S. (Amruta Shelar) and A.V.S. and R.P.; writing-review and editing, A.V.S., M.F.S., R.S.M. and V.T., P.L., A.L.; graphic design and visualization, A.S. (Amruta Shelar), R.S.M., M.F.S. and A.V.S.; supervision, R.P., A.V.S. and D.G.; project administration, A.V.S., R.P., M.C.; funding acquisition, A.V.S. \& R.P. All authors have read and agreed to the published version of the manuscript.

Funding: This research received no external funding.

Institutional Review Board Statement: Not applicable.

Informed Consent Statement: Not applicable.

Data Availability Statement: Data available in a publicly accessible repository.

Acknowledgments: This work was supported by BfR SFP 1322-725; BfR SFP 1322-735 (A.V.S.).

Conflicts of Interest: The authors declare no competing financial interest.

\section{References}

1. Fróna, D.; Szenderák, J.; Harangi-Rákos, M. The Challenge of Feeding the World. Sustainability 2019, 11, 5816. [CrossRef]

2. Umesha, S.; Manukumar, H.M.G.; Chandrasekhar, B. Chapter 3-Sustainable Agriculture and Food Security. In Biotechnology for Sustainable Agriculture; Singh, R.L., Mondal, S., Eds.; Woodhead Publishing: Cambridge, UK, 2018; pp. 67-91. [CrossRef]

3. Durán-Lara, E.F.; Valderrama, A.; Marican, A. Natural Organic Compounds for Application in Organic Farming. Agriculture 2020, 10, 41. [CrossRef]

4. Paparella, S.; Araújo, S.S.; Rossi, G.; Wijayasinghe, M.; Carbonera, D.; Balestrazzi, A. Seed priming: State of the art and new perspectives. Plant Cell Rep. 2015, 34, 1281-1293. [CrossRef] [PubMed]

5. Waqas, M.; Korres, N.E.; Khan, M.D.; Nizami, A.-S.; Deeba, F.; Ali, I.; Hussain, H. Advances in the Concept and Methods of Seed Priming. In Priming and Pretreatment of Seeds and Seedlings: Implication in Plant Stress Tolerance and Enhancing Productivity in Crop Plants; Hasanuzzaman, M., Fotopoulos, V., Eds.; Springer Singapore: Singapore, 2019; pp. 11-41. [CrossRef]

6. Marthandan, V.; Geetha, R.; Kumutha, K.; Renganathan, V.G.; Karthikeyan, A.; Ramalingam, J. Seed Priming: A Feasible Strategy to Enhance Drought Tolerance in Crop Plants. Int. J. Mol. Sci. 2020, 21, 8258. [CrossRef]

7. do Espirito Santo Pereira, A.; Caixeta Oliveira, H.; Fernandes Fraceto, L.; Santaella, C. Nanotechnology Potential in Seed Priming for Sustainable Agriculture. Nanomaterials 2021, 11, 267. [CrossRef]

8. Khodakovskaya, M.; Dervishi, E.; Mahmood, M.; Xu, Y.; Li, Z.; Watanabe, F.; Biris, A.S. Carbon Nanotubes Are Able To Penetrate Plant Seed Coat and Dramatically Affect Seed Germination and Plant Growth. ACS Nano 2009, 3, 3221-3227. [CrossRef] [PubMed]

9. Abbasi Khalaki, M.; Moameri, M.; Asgari Lajayer, B.; Astatkie, T. Influence of nano-priming on seed germination and plant growth of forage and medicinal plants. Plant Growth Regul. 2021, 93, 13-28. [CrossRef] 
10. Shang, Y.; Hasan, M.K.; Ahammed, G.J.; Li, M.; Yin, H.; Zhou, J. Applications of Nanotechnology in Plant Growth and Crop Protection: A Review. Molecules 2019, 24, 2558. [CrossRef]

11. Ioannou, A.; Gohari, G.; Papaphilippou, P.; Panahi Rad, S.; Akbari, A.; Dadpour, M.; Krasia-Christoforou, T.; Fotopoulos, V. Advanced nanomaterials in agriculture under a changing climate: The way to The future? Environ. Exp. Bot. 2020, 176. [CrossRef]

12. Gohari, G.; Panahirad, S.; Sadeghi, M.; Akbari, A.; Zareei, E.; Zahedi, S.M.; Bahrami, M.K.; Fotopoulos, V. Putrescinefunctionalized carbon quantum dot (put-CQD) nanoparticles effectively prime grapevine (Vitis vinifera cv. 'Sultana') against salt stress. BMC Plant Biol. 2021, 21, 120. [CrossRef]

13. Gohari, G.; Zareei, E.; Rostami, H.; Panahirad, S.; Kulak, M.; Farhadi, H.; Amini, M.; Martinez-Ballesta, M.d.C.; Fotopoulos, V. Protective effects of cerium oxide nanoparticles in grapevine (Vitis vinifera L.) cv. Flame Seedless under salt stress conditions. Ecotoxicol. Environ. Saf. 2021, 220, 112402. [CrossRef]

14. Azimi, F.; Oraei, M.; Gohari, G.; Panahirad, S.; Farmarzi, A. Chitosan-selenium nanoparticles (Cs-Se NPs) modulate the photosynthesis parameters, antioxidant enzymes activities and essential oils in Dracocephalum moldavica L. under cadmium toxicity stress. Plant Physiol. Biochem. 2021, 167, 257-268. [CrossRef]

15. Masoudniaragh, A.; Oraei, M.; Gohari, G.; Akbari, A.; Faramarzi, A. Using halloysite nanotubes as carrier for proline to alleviate salt stress effects in sweet basil (Ocimum basilicum L.). Sci. Hortic. 2021, 285, 110202. [CrossRef]

16. Sheikhalipour, M.; Esmaielpour, B.; Behnamian, M.; Gohari, G.; Giglou, M.T.; Vachova, P.; Rastogi, A.; Bresti, M.; Skalicky, M.J.N. Chitosan Selenium Nanoparticle (C" Se NP) Foliar Spray Alleviates Salt Stress in Bitter Melon. Nanomaterials 2021, 11, 684. [CrossRef]

17. Sheikhalipour, M.; Esmaielpour, B.; Gohari, G.; Haghighi, M.; Jafari, H.; Farhadi, H.; Kulak, M.; Kalisz, A. Salt Stress Mitigation via the Foliar Application of Chitosan-Functionalized Selenium and Anatase Titanium Dioxide Nanoparticles in Stevia (Stevia rebaudiana Bertoni). Molecules 2021, 26, 4090. [CrossRef] [PubMed]

18. Mohammadi, M.H.Z.; Panahirad, S.; Navai, A.; Bahrami, M.K.; Kulak, M.; Gohari, G. Cerium oxide nanoparticles (CeO2-NPs) improve growth parameters and antioxidant defense system in Moldavian Balm (Dracocephalum moldavica L.) under salinity stress. Plant Stress 2021, 1, 100006. [CrossRef]

19. Sanzari, I.; Leone, A.; Ambrosone, A. Nanotechnology in Plant Science: To Make a Long Story Short. Front. Bioeng. Biotechnol. 2019, 7, 120. [CrossRef]

20. Kaur, R.; Chandra, J.; Keshavkant, S. Nanotechnology: An efficient approach for rejuvenation of aged seeds. Physiol. Mol. Biol. Plants 2021, 27, 399-415. [CrossRef]

21. Mittal, D.; Kaur, G.; Singh, P.; Yadav, K.; Ali, S.A. Nanoparticle-Based Sustainable Agriculture and Food Science: Recent Advances and Future Outlook. Front. Bioeng. Biotechnol. 2020, 2, 9954. [CrossRef]

22. Duhan, J.S.; Kumar, R.; Kumar, N.; Kaur, P.; Nehra, K.; Duhan, S. Nanotechnology: The new perspective in precision agriculture. Biotechnol. Rep. 2017, 15, 11-23. [CrossRef]

23. Damalas, C.A.; Koutroubas, S.D.; Fotiadis, S. Hydro-Priming Effects on Seed Germination and Field Performance of Faba Bean in Spring Sowing. Agriculture 2019, 9, 201. [CrossRef]

24. Patade, V.Y.; Bhargava, S.; Suprasanna, P. Halopriming imparts tolerance to salt and PEG induced drought stress in sugarcane. Agric. Ecosyst. Environ. 2009, 134, 24-28. [CrossRef]

25. Chen, K.; Arora, R. Dynamics of the antioxidant system during seed osmopriming, post-priming germination, and seedling establishment in Spinach (Spinacia oleracea). Plant Sci. Int. J. Exp. Plant Biol. 2011, 180, 212-220. [CrossRef]

26. Moori, S.; Ahmadi-Lahijani, M.J. Hormopriming instigates defense mechanisms in Thyme (Thymus vulgaris L.) seeds under cadmium stress. J. Appl. Res. Med. Aromat. Plants 2020, 19, 100268. [CrossRef]

27. Sen, S.K.; Chouhan, D.; Das, D.; Ghosh, R.; Mandal, P. Improvisation of salinity stress response in mung bean through solid matrix priming with normal and nano-sized chitosan. Int. J. Biol. Macromol. 2020, 145, 108-123. [CrossRef]

28. Rakshit, A.; Sunita, K.; Pal, S.; Singh, A.; Singh, H. Bio-Priming Mediated Nutrient Use Efficiency of Crop Species; Springer: New Delhi, India, 2015; pp. 181-191. [CrossRef]

29. Nasrollahzadeh, M.; Sajadi, S.M.; Sajjadi, M.; Issaabadi, Z. Chapter 1-An Introduction to Nanotechnology. In Interface Science and Technology; Nasrollahzadeh, M., Sajadi, S.M., Sajjadi, M., Issaabadi, Z., Atarod, M., Eds.; Elsevier: Amsterdam, The Netherlands, 2019; Volume 28, pp. 1-27. [CrossRef]

30. García-Gómez, C.; Fernández, M.D. Chapter Four-Impacts of metal oxide nanoparticles on seed germination, plant growth and development. In Comprehensive Analytical Chemistry; Verma, S.K., Das, A.K., Eds.; Elsevier: Amsterdam, The Netherlands, 2019; Volume 84, pp. 75-124. [CrossRef]

31. Prasad, R.; Bhattacharyya, A.; Nguyen, Q.D. Nanotechnology in Sustainable Agriculture: Recent Developments, Challenges, and Perspectives. Front. Microbiol. 2017, 8, 1014. [CrossRef]

32. Chen, H. Metal based nanoparticles in agricultural system: Behavior, transport, and interaction with plants. Chem. Speciat. Bioavailab. 2018, 30, 123-134. [CrossRef]

33. Bandala, E.R.; Berli, M. Nanomaterials: New Agrotechnology Tools to Improve Soil Quality? In Agricultural Nanobiotechnology: Modern Agriculture for a Sustainable Future; López-Valdez, F., Fernández-Luqueño, F., Eds.; Springer International Publishing: Cham, The Netherlands, 2018; pp. 127-140. [CrossRef]

34. Lowry, G.V.; Avellan, A.; Gilbertson, L.M. Opportunities and challenges for nanotechnology in the agri-tech revolution. Nat. Nanotechnol. 2019, 14, 517-522. [CrossRef] [PubMed] 
35. Mahakham, W.; Sarmah, A.K.; Maensiri, S.; Theerakulpisut, P. Nanopriming technology for enhancing germination and starch metabolism of aged rice seeds using phytosynthesized silver nanoparticles. Sci. Rep. 2017, 7, 8263. [CrossRef] [PubMed]

36. Vera-Reyes, I.; Vázquez-Núñez, E.; Lira-Saldivar, R.H.; Méndez-Argüello, B. Effects of Nanoparticles on Germination, Growth, and Plant Crop Development. In Agricultural Nanobiotechnology: Modern Agriculture for a Sustainable Future; López-Valdez, F., Fernández-Luqueño, F., Eds.; Springer International Publishing: Berlin/Heidelberg, Germany, 2018; pp. 77-110. [CrossRef]

37. Szőllősi, R.; Molnár, Á.; Kondak, S.; Kolbert, Z. Dual Effect of Nanomaterials on Germination and Seedling Growth: Stimulation vs. Phytotoxicity. Plants 2020, 9, 1745. [CrossRef]

38. Choudhary, R.C.; Kumaraswamy, R.V.; Kumari, S.; Sharma, S.S.; Pal, A.; Raliya, R.; Biswas, P.; Saharan, V. Zinc encapsulated chitosan nanoparticle to promote maize crop yield. Int. J. Biol. Macromol. 2019, 127, 126-135. [CrossRef]

39. Saharan, V.; Kumaraswamy, R.V.; Choudhary, R.C.; Kumari, S.; Pal, A.; Raliya, R.; Biswas, P. Cu-Chitosan Nanoparticle Mediated Sustainable Approach To Enhance Seedling Growth in Maize by Mobilizing Reserved Food. J. Agric. Food Chem. 2016, 64, 6148-6155. [CrossRef] [PubMed]

40. Pereira, A.d.E.S.; Oliveira, H.C.; Fraceto, L.F. Polymeric nanoparticles as an alternative for application of gibberellic acid in sustainable agriculture: A field study. Sci. Rep. 2019, 9, 7135. [CrossRef] [PubMed]

41. Falsini, S.; Clemente, I.; Papini, A.; Tani, C.; Schiff, S.; Salvatici, M.C.; Petruccelli, R.; Benelli, C.; Giordano, C.; Gonnelli, C.; et al. When Sustainable Nanochemistry Meets Agriculture: Lignin Nanocapsules for Bioactive Compound Delivery to Plantlets. ACS Sustain. Chem. Eng. 2019, 7, 19935-19942. [CrossRef]

42. Chau, N.H.; Doan, Q.H.; Chu, T.H.; Nguyen, T.T.; Dao Trong, H.; Ngo, Q.B. Effects of Different Nanoscale MicroelementContaining Formulations for Presowing Seed Treatment on Growth of Soybean Seedlings. J. Chem. 2019, 2019, 8060316. [CrossRef]

43. Joshi, A.; Kaur, S.; Dharamvir, K.; Nayyar, H.; Verma, G. Multi-walled carbon nanotubes applied through seed-priming influence early germination, root hair, growth and yield of bread wheat (Triticum aestivum L.). J. Sci. Food Agric. 2018, 98, 3148-3160. [CrossRef]

44. Acharya, P.; Jayaprakasha, G.K.; Crosby, K.M.; Jifon, J.L.; Patil, B.S. Nanoparticle-Mediated Seed Priming Improves Germination, Growth, Yield, and Quality of Watermelons (Citrullus lanatus) at multi-locations in Texas. Sci. Rep. 2020, 10, 5037. [CrossRef]

45. Sundaria, N.; Singh, M.; Upreti, P.; Chauhan, R.; Jaiswal, J.P.; Kumar, A. Seed Priming with Iron Oxide Nanoparticles Triggers Iron Acquisition and Biofortification in Wheat (Triticum aestivum L.) Grains. J. Plant. Growth Regul. 2019, 38, 122-131. [CrossRef]

46. Abdel Latef, A.A.H.; Abu Alhmad, M.F.; Abdelfattah, K.E. The Possible Roles of Priming with ZnO Nanoparticles in Mitigation of Salinity Stress in Lupine (Lupinus termis) Plants. J. Plant Growth Regul. 2017, 36, 60-70. [CrossRef]

47. Savassa, S.M.; Duran, N.M.; Rodrigues, E.S.; de Almeida, E.; van Gestel, C.A.M.; Bompadre, T.F.V.; de Carvalho, H.W.P. Effects of ZnO Nanoparticles on Phaseolus vulgaris Germination and Seedling Development Determined by X-ray Spectroscopy. ACS Appl. Nano Mater. 2018, 1, 6414-6426. [CrossRef]

48. Duran, N.M.; Savassa, S.M.; Lima, R.G.d.; de Almeida, E.; Linhares, F.S.; van Gestel, C.A.M.; Pereira de Carvalho, H.W. X-ray Spectroscopy Uncovering the Effects of Cu Based Nanoparticle Concentration and Structure on Phaseolus vulgaris Germination and Seedling Development. J. Agric. Food Chem. 2017, 65, 7874-7884. [CrossRef] [PubMed]

49. Ahuja, R.; Sidhu, A.; Bala, A. Synthesis and evaluation of iron(ii) sulfide aqua nanoparticles (FeS-NPs) against Fusarium verticillioides causing sheath rot and seed discoloration of rice. Eur. J. Plant Pathol. 2019, 155, 163-171. [CrossRef]

50. Ye, Y.; Cota-Ruiz, K.; Hernández-Viezcas, J.A.; Valdés, C.; Medina-Velo, I.A.; Turley, R.S.; Peralta-Videa, J.R.; Gardea-Torresdey, J.L. Manganese Nanoparticles Control Salinity-Modulated Molecular Responses in Capsicum annuum L. through Priming: A Sustainable Approach for Agriculture. ACS Sustain. Chem. Eng. 2020, 8, 1427-1436. [CrossRef]

51. Li, R.; He, J.; Xie, H.; Wang, W.; Bose, S.K.; Sun, Y.; Hu, J.; Yin, H. Effects of chitosan nanoparticles on seed germination and seedling growth of wheat (Triticum aestivum L.). Int. J. Biol. Macromol. 2019, 126, 91-100. [CrossRef]

52. Hussain, A.; Rizwan, M.; Ali, Q.; Ali, S. Seed priming with silicon nanoparticles improved the biomass and yield while reduced the oxidative stress and cadmium concentration in wheat grains. Environ. Sci. Pollut. Res. Int. 2019, 26, 7579-7588. [CrossRef]

53. Maswada, H.F.; Djanaguiraman, M.; Prasad, P.V.V. Seed treatment with nano-iron (III) oxide enhances germination, seeding growth and salinity tolerance of sorghum. J. Agron. Crop. Sci. 2018, 204, 577-587. [CrossRef]

54. Kasote, D.M.; Lee, J.H.J.; Jayaprakasha, G.K.; Patil, B.S. Seed Priming with Iron Oxide Nanoparticles Modulate Antioxidant Potential and Defense-Linked Hormones in Watermelon Seedlings. ACS Sustain. Chem. Eng. 2019, 7, 5142-5151. [CrossRef]

55. Gnanasekaran, D.k.; Raja, K.; Natarajan, N.; Govindaraju, K.; Subramanian, K. Invigouration treatment of metal and metal oxide nanoparticles for improving the seed quality of aged chilli seeds (Capsicum annum L.). Mater. Chem. Phys. 2019, $242,122492$. [CrossRef]

56. Kibinza, S.; Bazin, J.; Bailly, C.; Farrant, J.; Corbineau, F.; El-Maarouf-Bouteau, H. Catalase is a key enzyme in seed recovery from ageing during priming. Plant Sci. Int. J. Exp. Plant Biol. 2011, 181, 309-315. [CrossRef]

57. Maurel, C.; Boursiac, Y.; Luu, D.-T.; Santoni, V.; Shahzad, Z.; Verdoucq, L. Aquaporins in Plants. Physiol. Rev. 2015, 95, 1321-1358. [CrossRef]

58. Bienert, G.P.; Chaumont, F. Aquaporin-facilitated transmembrane diffusion of hydrogen peroxide. Biochim. Biophys. Acta 2014, 1840, 1596-1604. [CrossRef]

59. Müller, K.; Linkies, A.; Vreeburg, R.A.M.; Fry, S.C.; Krieger-Liszkay, A.; Leubner-Metzger, G. In Vivo Cell Wall Loosening by Hydroxyl Radicals during Cress Seed Germination and Elongation Growth. Plant Physiol. 2009, 150, 1855. [CrossRef] [PubMed]

60. Gomes, M.P.; Garcia, Q.S. Reactive oxygen species and seed germination. Biologia 2013, 68, 351-357. [CrossRef] 
61. Ernest, V.; Shiny, P.J.; Mukherjee, A.; Chandrasekaran, N. Silver nanoparticles: A potential nanocatalyst for the rapid degradation of starch hydrolysis by $\alpha$-amylase. Carbohydr. Res. 2012, 352, 60-64. [CrossRef]

62. An, J.; Hu, P.; Li, F.; Wu, H.; Shen, Y.; White, J.C.; Tian, X.; Li, Z.; Giraldo, J.P. Emerging investigator series: Molecular mechanisms of plant salinity stress tolerance improvement by seed priming with cerium oxide nanoparticles. Environ. Sci. Nano 2020, 7 , 2214-2228. [CrossRef]

63. Siddaiah, C.N.; Prasanth, K.V.H.; Satyanarayana, N.R.; Mudili, V.; Gupta, V.K.; Kalagatur, N.K.; Satyavati, T.; Dai, X.-F.; Chen, J.-Y.; Mocan, A.; et al. Chitosan nanoparticles having higher degree of acetylation induce resistance against pearl millet downy mildew through nitric oxide generation. Sci. Rep. 2018, 8, 2485. [CrossRef] [PubMed]

64. Misson, M.; Zhang, H.; Jin, B. Nanobiocatalyst advancements and bioprocessing applications. J. R. Soc. Interface 2015, $12,20140891$. [CrossRef]

65. Raza, A.; Razzaq, A.; Mehmood, S.S.; Zou, X.; Zhang, X.; Lv, Y.; Xu, J. Impact of Climate Change on Crops Adaptation and Strategies to Tackle Its Outcome: A Review. Plants 2019, 8, 34. [CrossRef]

66. Chojak-Koźniewska, J.; Kuźniak, E.; Zimny, J. The Effects of Combined Abiotic and Pathogen Stress in Plants: Insights From Salinity and Pseudomonas syringae pv lachrymans Interaction in Cucumber. Front. Plant Sci. 2018, 9, 1691. [CrossRef]

67. Aslani, F.; Bagheri, S.; Muhd Julkapli, N.; Juraimi, A.S.; Hashemi, F.S.G.; Baghdadi, A. Effects of Engineered Nanomaterials on Plants Growth: An Overview. Sci. World J. 2014, 2014, 641759. [CrossRef]

68. Ansari, M.H.D.; Lavhale, S.; Kalunke, R.M.; Srivastava, P.L.; Pandit, V.; Gade, S.; Yadav, S.; Laux, P.; Luch, A.; Gemmati, D.; et al. Recent Advances in Plant Nanobionics and Nanobiosensors for Toxicology Applications. Curr. Nanosci. 2020, $16,27-41$. [CrossRef]

69. Baz, H.; Creech, M.; Chen, J.; Gong, H.; Bradford, K.; Huo, H. Water-Soluble Carbon Nanoparticles Improve Seed Germination and Post-Germination Growth of Lettuce under Salinity Stress. Plants 2020, 10, 1192.

70. Naguib, D.M.; Abdalla, H. Metabolic Status during Germination of Nano Silica Primed Zea mays Seeds under Salinity Stress. J. Crop Sci. Biotechnol. 2019, 22, 415-423. [CrossRef]

71. Khan, Z.S.; Rizwan, M.; Hafeez, M.; Ali, S.; Javed, M.R.; Adrees, M. The accumulation of cadmium in wheat (Triticum aestivum) as influenced by zinc oxide nanoparticles and soil moisture conditions. Environ. Sci. Pollut. Res. Int. 2019, 26, 19859-19870. [CrossRef]

72. Ivani, R.; Sanaei Nejad, S.H.; Ghahraman, B.; Astaraei, A.R.; Feizi, H. Role of bulk and Nanosized SiO(2) to overcome salt stress during Fenugreek germination (Trigonella foenum-graceum L.). Plant Signal. Behav. 2018, 13, e1044190. [CrossRef]

73. Hojjat, S.S.; Kamyab, M. The effect of silver nanoparticle on Fenugreek seed germination under salinity levels. Russ. Agric. Sci. 2017, 43, 61-65. [CrossRef]

74. Konate, A.; He, X.; Zhang, Z.; Ma, Y.; Zhang, P.; Alugongo, G.M.; Rui, Y. Magnetic (Fe3O4) Nanoparticles Reduce Heavy Metals Uptake and Mitigate Their Toxicity in Wheat Seedling. Sustainability 2017, 9, 790. [CrossRef]

75. Sathiyabama, M.; Muthukumar, S. Chitosan guar nanoparticle preparation and its in vitro antimicrobial activity towards phytopathogens of rice. Int. J. Biol. Macromol. 2020, 153, 297-304. [CrossRef]

76. Xu, T.; Ma, C.; Aytac, Z.; Hu, X.; Ng, K.W.; White, J.C.; Demokritou, P. Enhancing Agrichemical Delivery and Seedling Development with Biodegradable, Tunable, Biopolymer-Based Nanofiber Seed Coatings. ACS Sustain. Chem. Eng. 2020, 8 , 9537-9548. [CrossRef]

77. Bravo Cadena, M.; Preston, G.M.; Van der Hoorn, R.A.L.; Flanagan, N.A.; Townley, H.E.; Thompson, I.P. Enhancing cinnamon essential oil activity by nanoparticle encapsulation to control seed pathogens. Ind. Crop. Prod. 2018, 124, 755-764. [CrossRef]

78. Vejan, P.; Abdullah, R.; Khadiran, T.; Ismail, S.; Nasrulhaq Boyce, A. Role of Plant Growth Promoting Rhizobacteria in Agricultural Sustainability-A Review. Molecules 2016, 21, 573. [CrossRef] [PubMed]

79. Kumari, B.; Mallick, M.A.; Solanki, M.K.; Hora, A.; Mani, M. 8-Applying nanotechnology to bacteria: An emerging technology for sustainable agriculture. In Role of Plant Growth Promoting Microorganisms in Sustainable Agriculture and Nanotechnology; Kumar, A., Singh, A.K., Choudhary, K.K., Eds.; Woodhead Publishing: Cambridge, UK, 2019; pp. 121-143. [CrossRef]

80. Shcherbakova, E.; Shcherbakov, A.; Andronov, E.; Gonchar, L.; Kalenska, S.; Chebotar, V. Combined pre-seed treatment with microbial inoculants and Mo nanoparticles changes composition of root exudates and rhizosphere microbiome structure of chickpea (Cicer arietinum L.) plants. Symbiosis 2017, 73, 57-69. [CrossRef]

81. De Gregorio, P.R.; Michavila, G.; Ricciardi Muller, L.; de Souza Borges, C.; Pomares, M.F.; Saccol de Sá, E.L.; Pereira, C.; Vincent, P.A. Beneficial rhizobacteria immobilized in nanofibers for potential application as soybean seed bioinoculants. PLoS ONE 2017, 12, e0176930. [CrossRef] [PubMed]

82. Taran, N.Y.; Gonchar, O.M.; Lopatko, K.G.; Batsmanova, L.M.; Patyka, M.V.; Volkogon, M.V. The effect of colloidal solution of molybdenum nanoparticles on the microbial composition in rhizosphere of Cicer arietinum L. Nanoscale Res. Lett. $2014,9,289$. [CrossRef]

83. Jiang, J.; He, X.; Li, L.; Li, J.; Shao, H.; Xu, Q.; Ye, R.; Dong, Y. Effect of Cold Plasma Treatment on Seed Germination and Growth of Wheat. Plasma Sci. Technol. 2013, 16, 54. [CrossRef]

84. Jiang, J.; Lu, Y.; Li, J.; Li, L.; He, X.; Shao, H.; Dong, Y. Effect of Seed Treatment by Cold Plasma on the Resistance of Tomato to Ralstonia solanacearum (Bacterial Wilt). PLoS ONE 2014, 9, e97753. [CrossRef]

85. Volin, J.; Denes, F.S.; Young, R.A.; Park, S.M.T. Modification of seed germination performance through cold plasma chemistry technology. Crop Sci. 2000, 40, 1706-1718. [CrossRef] 
86. Mildažienė, V.; Aleknavičiūtè, V.; Žūkienè, R.; Paužaitè, G.; Naučienè, Z.; Filatova, I.; Lyushkevich, V.; Haimi, P.; Tamošiūnè, I.; Baniulis, D. Treatment of Common Sunflower (Helianthus annus L.) Seeds with Radio-frequency Electromagnetic Field and Cold Plasma Induces Changes in Seed Phytohormone Balance, Seedling Development and Leaf Protein Expression. Sci. Rep. 2019, 9, 6437. [CrossRef]

87. Ling, L.; Jiafeng, J.; Jiangang, L.; Minchong, S.; Xin, H.; Hanliang, S.; Yuanhua, D. Effects of cold plasma treatment on seed germination and seedling growth of soybean. Sci. Rep. 2014, 4, 5859. [CrossRef]

88. Babajani, A.; Iranbakhsh, A.; Oraghi Ardebili, Z.; Eslami, B. Seed Priming with Non-thermal Plasma Modified Plant Reactions to Selenium or Zinc Oxide Nanoparticles: Cold Plasma as a Novel Emerging Tool for Plant Science. Plasma Chem. Plasma Process. 2019, 39, 21-34. [CrossRef]

89. Abedi, S.; Iranbakhsh, A.; Oraghi Ardebili, Z.; Ebadi, M. Seed priming with cold plasma improved early growth, flowering, and protection of Cichorium intybus against selenium nanoparticle. J. Theor. Appl. Phys. 2020, 14, 113-119. [CrossRef]

90. Moghanloo, M.; Iranbakhsh, A.; Ebadi, M.; Oraghi Ardebili, Z. Differential physiology and expression of phenylalanine ammonia lyase (PAL) and universal stress protein (USP) in the endangered species Astragalus fridae following seed priming with cold plasma and manipulation of culture medium with silica nanoparticles. 3 Biotech 2019, 9, 288. [CrossRef] [PubMed]

91. Iranbakhsh, A.; Oraghi Ardebili, Z.; Oraghi Ardebili, N.; Ghoranneviss, M.; Safari, N. Cold plasma relieved toxicity signs of nano zinc oxide in Capsicum annuum cayenne via modifying growth, differentiation, and physiology. Acta Physiol. Plant. 2018, 40, 154. [CrossRef]

92. Colmer, J.; O’Neill, C.M.; Wells, R.; Bostrom, A.; Reynolds, D.; Websdale, D.; Shiralagi, G.; Lu, W.; Lou, Q.; Le Cornu, T.; et al. SeedGerm: A cost-effective phenotyping platform for automated seed imaging and machine-learning based phenotypic analysis of crop seed germination. New Phytol. 2020, 228, 778-793. [CrossRef]

93. Nguyen, T.; Hoang, V.-N.; Le, T.; Tran, T.-H.; Hai, V. A Vision Based Method for Automatic Evaluation of Germination Rate of Rice Seeds. In Proceedings of the 1st International Conference on Multimedia Analysis and Pattern Recognition (MAPR), Ho Chi Minh, Vietnam, 5-6 April 2018; pp. 1-6. [CrossRef]

94. Zhou, J.; Applegate, C.; Alonso, A.; Reynolds, D.; Orford, S.; Mackiewicz, M.; Griffiths, S.; Penfield, S.; Pullen, N. Leaf-GP: An open and automated software application for measuring growth phenotypes for arabidopsis and wheat. Plant Methods 2017, 13, 117. [CrossRef]

95. Falk, K.G.; Jubery, T.Z.; Mirnezami, S.V.; Parmley, K.A.; Sarkar, S.; Singh, A.; Ganapathysubramanian, B.; Singh, A.K. Computer vision and machine learning enabled soybean root phenotyping pipeline. Plant Methods 2020, 16, 5. [CrossRef] [PubMed]

96. Genze, N.; Bharti, R.; Grieb, M.; Schultheiss, S.J.; Grimm, D.G. Accurate machine learning-based germination detection, prediction and quality assessment of three grain crops. Plant Methods 2020, 16, 157. [CrossRef]

97. Dell'Aquila, A. Digital Imaging Information Technology Applied to Seed Germination Testing: A Review. Agron. Sustain. Dev. 2009, 29, 213-221. [CrossRef]

98. Dantas de Medeiros, A.; Silva, L.; Ribeiro, J.P.; Ferreira, K.; Fim Rosas, J.; Santos, A.; Barboza da Silva, C. Machine Learning for Seed Quality Classification: An Advanced Approach Using Merger Data from FT-NIR Spectroscopy and X-ray Imaging. Sensors 2020, 20, 4319. [CrossRef]

99. Singh, A.V.; Chandrasekar, V.; Janapareddy, P.; Mathews, D.E.; Laux, P.; Luch, A.; Yang, Y.; Garcia-Canibano, B.; Balakrishnan, S.; Abinahed, J.; et al. Emerging Application of Nanorobotics and Artificial Intelligence To Cross the BBB: Advances in Design, Controlled Maneuvering, and Targeting of the Barriers. ACS Chem. Neurosci. 2021, 12, 1835-1853. [CrossRef]

100. Singh, A.V.; Maharjan, R.S.; Jungnickel, H.; Romanowski, H.; Hachenberger, Y.U.; Reichardt, P.; Bierkandt, F.; Siewert, K.; Gadicherla, A.; Laux, P.; et al. Evaluating Particle Emissions and Toxicity of 3D Pen Printed Filaments with Metal Nanoparticles As Additives: In Vitro and in Silico Discriminant Function Analysis. ACS Sustain. Chem. Eng. 2021, 9, 11724-11737. [CrossRef]

101. Joosen, R.V.L.; Kodde, J.; Willems, L.A.J.; Ligterink, W.; van der Plas, L.H.W.; Hilhorst, H.W.M. GERMINATOR: A software package for high-throughput scoring and curve fitting of Arabidopsis seed germination. Plant J. 2010, 62, 148-159. [CrossRef] [PubMed]

102. Hoffmaster, A.F.; Xu, L.; Fujimura, K.; Bennett, M.A.; Evans, A.F.; McDonald, M.B. The Ohio State University Seed Vigor Imaging System (SVIS) for Soybean and Corn Seedlings. Seed Technol. 2005, 27, 7-24.

103. Charavay, C.; Segard, S.; Pochon, N.; Nussaume, L.; Javot, H. SeedUSoon: A New Software Program to Improve Seed Stock Management and Plant Line Exchanges between Research Laboratories. Front. Plant Sci. 2017, 8. [CrossRef]

104. Tanabata, T.; Shibaya, T.; Hori, K.; Ebana, K.; Yano, M. SmartGrain: High-throughput phenotyping software for measuring seed shape through image analysis. Plant Physiol 2012, 160, 1871-1880. [CrossRef]

105. Zhu, F.; Paul, P.; Hussain, W.; Wallman, K.; Dhatt, B.K.; Sandhu, J.; Irvin, L.; Morota, G.; Yu, H.; Walia, H. SeedExtractor: An Open-Source GUI for Seed Image Analysis. Plant Sci. 2021, 11, 1546. [CrossRef]

106. Komyshev, E.; Genaev, M.; Afonnikov, D. Evaluation of the SeedCounter, A Mobile Application for Grain Phenotyping. Front. Plant Sci. 2017, 7, 1990. [CrossRef]

107. Marmiroli, N.; White, J.C. Editorial: Nanotoxicology and Environmental Risk Assessment of Engineered Nanomaterials (ENMs) in Plants. Front. Plant Sci. 2016, 7, 1370. [CrossRef] [PubMed]

108. Wang, W.; He, A.; Peng, S.; Huang, J.; Cui, K.; Nie, L. The Effect of Storage Condition and Duration on the Deterioration of Primed Rice Seeds. Plant Sci. 2018, 9, 172. [CrossRef] 
109. Farooq, M.; Usman, M.; Nadeem, F.; Rehman, H.; Wahid, A.; Basra, S.; Siddique, K. Seed priming in field crops—Potential benefits, adoption and challenges. Crop Pasture Sci. 2019, 70, 731-771. [CrossRef]

110. Kah, M.; Tufenkji, N.; White, J.C. Nano-enabled strategies to enhance crop nutrition and protection. Nat. Nanotechnol. 2019, 14, 532-540. [CrossRef] [PubMed]

111. Garg, M.; Sharma, N.; Sharma, S.; Kapoor, P.; Kumar, A.; Chunduri, V.; Arora, P. Biofortified Crops Generated by Breeding, Agronomy, and Transgenic Approaches Are Improving Lives of Millions of People around the World. Front. Nutr. $2018,5,12$. [CrossRef] [PubMed]

112. Gilbertson, L.M.; Pourzahedi, L.; Laughton, S.; Gao, X.; Zimmerman, J.B.; Theis, T.L.; Westerhoff, P.; Lowry, G.V. Guiding the design space for nanotechnology to advance sustainable crop production. Nat. Nanotechnol. 2020, 15, 801-810. [CrossRef] [PubMed] 